OPEN ACCESS

Mitigated Start-Up of PEMFC in Real Automotive Conditions: Local Experimental Investigation and Development of a New Accelerated Stress Test Protocol

To cite this article: Andrea Bisello et al 2021 J. Electrochem. Soc. 168054501

View the article online for updates and enhancements. 


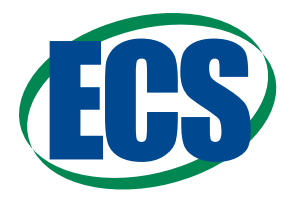

\title{
Mitigated Start-Up of PEMFC in Real Automotive Conditions: Local Experimental Investigation and Development of a New Accelerated Stress Test Protocol
}

\author{
Andrea Bisello, ${ }^{1, z}$ (ib Elena Colombo, ${ }^{1}$ (i) Andrea Baricci, ${ }^{1}$ (i) Claudio Rabissi, ${ }^{1}$ (i) Laure Guetaz, \\ Pawel Gazdzicki, ${ }^{3}$ (i) and Andrea Casalegno ${ }^{1}$ (i) \\ ${ }^{1}$ Politecnico di Milano, Department of Energy, 20156 Milano, Italy \\ ${ }^{2}$ Université Grenoble Alpes, CEA, LITEN, 38054 Grenoble, France \\ ${ }^{3}$ German Aerospace Center (DLR), Institute of Engineering Thermodynamics, 70569 Stuttgart, Germany
}

\begin{abstract}
This study combines local electrochemical diagnostics with ex situ analysis to investigate degradation mechanism associated to start-up/shut-down (SU/SD) of PEMFC and mitigation strategies adopted in automotive stacks. Local degradation resulting from repeated SU/SD was analyzed with and without mitigation strategies by means of a macro-segmented cell setup provided with Reference Hydrogen Electrodes (RHEs) at both anode and cathode to measure local electrodes potential and current. Accelerated Stress Test (AST) for start-up with and without mitigation strategies are proposed and validated. A ten-fold acceleration of performance loss due to un-mitigated SU/SD has been calculated with respect to AST for catalyst support. Under mitigated SU/SD, instead, a strong degradation was observed as localized at cathode inlet region (i.e. $-38 \%$ ECSA loss and $-22 \mathrm{mV}$ voltage loss after 200 cycles) due to local potentials transient reaching up to $1.5 \mathrm{~V}$ vs RHE. These localized stress conditions were additionally reproduced in a zero-gradient and a new AST protocol (named start-up AST) was proposed to mimic the potential profile observed upon SU/SD cycling. Representativeness of the start-up AST for real world degradation was confirmed up to 200 cycles. Platinum dissolution and diffusion/precipitation within the polymer electrolyte was shown to be the dominant mechanism affecting performance loss.

(C) 2021 The Author(s). Published on behalf of The Electrochemical Society by IOP Publishing Limited. This is an open access article distributed under the terms of the Creative Commons Attribution Non-Commercial No Derivatives 4.0 License (CC BYNC-ND, http://creativecommons.org/licenses/by-nc-nd/4.0/), which permits non-commercial reuse, distribution, and reproduction in any medium, provided the original work is not changed in any way and is properly cited. For permission for commercial reuse, please email: permissions@ioppublishing.org. [DOI: 10.1149/1945-7111/abf77b]
\end{abstract}

Manuscript submitted December 18, 2020; revised manuscript received March 2, 2021. Published April 30, 2021. This paper is part of the JES Focus Issue on Proton Exchange Membrane Fuel Cell and Proton Exchange Membrane Water Electrolyzer Durability.

Supplementary material for this article is available online

Hydrogen polymer electrolyte membrane fuel cells (PEMFC) are suitable for replacing fossil fuels-based power systems of mediumlarge cars, buses and trucks. ${ }^{1,2}$ While the first passenger vehicles already entered the market, ${ }^{2}$ a significant improvement in durability is required to accelerate the commercialization and facilitate the spread of more demanding applications such as heavy duty transportation. ${ }^{3}$ The material degradation depends on the peculiarities of automotive application: possible operation modes include frequent load changes or temperature cycles, exposure to stressing events, e.g. cold start or the formation of hydrogen/air fronts in the anode compartment. This last aspect occurs after a long stop ${ }^{4}$ of several days, during which air diffuses into the anode compartment. Upon subsequent start-up (SU) hydrogen is injected in the anode compartment, forming a hydrogen/air front.

Several studies analyzed the degradation resulting from SU/SD and it was concluded that carbon corrosion in the cathode electrode is the major cause for voltage degradation, ${ }^{5}$ due to a reverse-current mechanism. ${ }^{6}$ Reiser et al. demonstrated in 2005 that the hydrogen/air front at the anode compartment causes a high potential excursion at cathode electrode as high as $1.5 / 1.6 \mathrm{~V}$ vs RHE, thus accelerating catalyst and carbon support degradation in the local regions exposed to air in the anode. Degradation is expected to be more severe near the hydrogen outlet (inlet) in the case of start-up (shut-down). ${ }^{7,8}$ The electrochemical oxidation of carbon support is possible at potentials above $0.207 \mathrm{~V}$ vs NHE according to reaction:

$$
\mathrm{C}+\mathrm{H}_{2} \mathrm{O} \rightarrow \mathrm{CO}_{2}+4 \mathrm{H}^{+}+4 \mathrm{e}^{-} \mathrm{E}_{0}=0.207 \mathrm{~V}
$$

However, the kinetics of carbon oxidation reaction (COR) is slow at typical PEMFC operating temperatures and potentials, and it

${ }^{\mathrm{z}}$ E-mail: andrea.bisello@polimi.it appears significant only at potentials above $0.6 \mathrm{~V}$, when the reaction is catalyzed by platinum as observed by Macauley et al. ${ }^{9}$

Numerous works in the literature focus on the conditions accelerating the carbon corrosion during SU/SD events. Shen et al. ${ }^{10}$ found that hydrogen or air flow rate influences the reversecurrent mechanism and suggested feeding the gas as fast as possible to limit degradation. Moreover, they proposed to purge nitrogen to reduce the fuel cell damaging during start-up.

The effect of gas flow rate was also analyzed by Lamibrac et al., ${ }^{7}$ who proposed an experimental approach based on a segmented-cell and on the measurements of local currents to estimate global and local carbon losses. First, they confirmed that flow rate must be as high as possible. In addition, they observed that degradation is strongly heterogeneous during start-up and that the performance loss is mostly located at the anode outlet region. Dillet et al. confirmed that for equivalent gas flow rates, start-ups are more damaging than shut-downs. ${ }^{11}$

In 2013, Durst et al. ${ }^{12}$ studied aging heterogeneity induced by 137 SU/SD events, when shut-down was performed at high velocity and start-up at low velocity. They found that the cathodic catalyst layer is less damaged at hydrogen inlet rather than at hydrogen outlet. Moreover, by ex situ analysis of aged samples they confirmed that the portion of cathode at the opposite side of anode land degraded more than portion opposite to anode channel, due to the higher difficulties in removing oxygen under land during start-ups.

Mittermeier et al. analyzed the effect of temperature ${ }^{13}$ and relative humidity ${ }^{14}$ under repeated start/stop cycles. They predicted a ten-fold lower degradation rate at $5{ }^{\circ} \mathrm{C}$ compared to $80{ }^{\circ} \mathrm{C}$, while a three-fold lower degradation rate at $\mathrm{RH}=25 \%$ compared to $100 \%$, measured at $80{ }^{\circ} \mathrm{C}$.

Thanks to these findings, several mitigation strategies were progressively implemented in PEMFC systems for SU/SD, which successfully improve durability. ${ }^{5,15}$ Such mitigation strategies are mainly focused on oxygen consumption using additional load during 
shut-down operation, ${ }^{16,17}$ gas purge strategies adopted in a proper sequence during $\mathrm{SU} / \mathrm{SD},{ }^{18}$ or performing the operation at low temperature. ${ }^{19}$

Even though many studies address SU/SD in PEMFC, only few discuss the impact of such mitigation strategies on the degradation mechanisms. Being, fuel cell SU/SD operation and mitigation strategies adopted in real systems, difficult to simulate reliably at lab-scale level, AST protocols have been widely adopted to evaluate catalyst degradation and identify materials with enhanced durability. In Refs. 20, 21, the most important protocols are summarized, highlighting differences and characteristics. Some of the most adopted protocols are proposed by the US Department of Energy (DoE) and the US Fuel Cell Council (USFCC). ${ }^{3}$ Of these, catalyst support AST is widely adopted and consists in 5,000 triangle sweep cycles between $1 \mathrm{~V}$ and $1.5 \mathrm{~V}$ to simulate $\mathrm{H}_{2}$-air front typical of start-up and accelerate support corrosion. However, the DoE protocol imposed fixed operating condition, i.e. $\mathrm{T}=80{ }^{\circ} \mathrm{C}, \mathrm{RH}=$ $100 \%$, and ambient pressure of supplied gases $\left(\mathrm{H}_{2}\right.$ at anode/ $\mathrm{N}_{2}$ at cathode) along with voltage limits, without accounting the influences of different operating and cycle conditions on the degradation rates.

Despite the many strategies existing, there is a clear lack in the scientific literature regarding the identification of the relevant degradation mechanisms involved in the mitigated SU and a comparison between this degradation mode and already existing ASTs that selectively induce catalyst or support degradation.

To address the above-mentioned gap, this article focuses on understanding mitigated SU/SD operation. This work follows the specification of the ID-FAST European project durability test program, built on use-case vehicle data (ID-FAST id: 779565). Accordingly, the start-up event (after a long stop—not to be mixed up with more frequent short stop) should occur with a frequency of one every 200 operating hours, i.e. approximately 30 times through the component lifetime, considering a durability target for a passenger vehicle of $6000 \mathrm{~h}$. In this range, the mitigation strategies applied are supposed to be effective to limit the components degradation, but the analysis carried out in this work was extended to 200 cycles to assess future applications with longer lifetime, e.g. heavy-duty. The definition of mitigated SU/SD protocol, here considered, as unavoidable stressor in realistic driving cycle, consists of a hydrogen/air front going through the anode compartment, only at start-up of the operations. This procedure simulates the scenario when a vehicle is kept off for a long period (several days/ weeks), so oxygen diffuses both at anode and cathode compartment in fuel cell stack due to leakages.

In this work, the impact of the start-up/shut-down on performance degradation, was evaluated by adopting two different protocols without and with such mitigation strategy. The results were quantitatively correlated with catalyst support AST and a new ad$h o c$ protocol for start-up developed in a reference zero-gradient cell hardware. $^{22,23}$ To clarify the link between start-up/shut-down operation and performance degradation, a locally resolved investigation was performed by electrochemical measurements and postmortem analysis of aged materials.

\section{Experimental Methodology}

MEA samples.-In this work, experimental activities are carried out on two type of catalyst-coated membranes (CCMs) to consolidate results generality, mainly differing in terms of membrane thickness and catalyst loadings. A standard commercial CCM manufactured by Ion Power Inc. (with Pt loading of $0.3 \mathrm{mg} \mathrm{cm}^{-2}$ for both anode and cathode side sprayed on Nafion ${ }^{\circledR}$ XL membrane and assembled with Sigrace ${ }^{\circledR}$ 29BC GDL) was tested together with an automotive commercial MEA supplied by Johnson Matthey (with Pt loading of $0.4 \mathrm{mg} \mathrm{cm}^{-2}$ for cathode and $0.08 \mathrm{mg} \mathrm{cm}^{-2}$ for anode, assembled with Freudenberg GDL H14CX483). For both the samples, assembled without hot-pressing, compression was obtained using rigid gaskets in PTFE aiming to $80 \%$ mechanical compression; the active area was delimited using few $\mu \mathrm{m}$-thick mylar sub-gaskets.
Experimental hardware.-Two different cell experimental setups, including cell hardware and testing station, have been developed and applied in this work, described in the following.

To be able to reproduce start-up/shut-down operation, cell feeding gas can be selected by means of three-way upstream valves among hydrogen, oxygen, nitrogen (from compressed bottles, purity level of 5.0, 5.0 and 5.5 respectively) and compressed air. The gas flow is regulated by means of flow meters (Brooks ${ }^{\circledR} 5850 \mathrm{~s}$ ) and fed to water bubblers (Fuel cell tech ${ }^{\circledR}$ ) to reach the desired dewpoint. Heated ducts are used immediately downstream to prevent condensation in the gas stream prior to reaching cell inlet manifold. Both temperature of heated ducts and bubblers is measured and regulated by means of T-controllers. Reactants pressure is regulated using electronically controlled backpressure valves (Equilibar ${ }^{\circledR}$ LF Series) installed at the outlet manifolds of the cell and measured by means of several pressure transducers $\left(\mathrm{GE}^{\circledR}\right.$ Unik 5000), connected both to anode/cathode inlet and outlet.

Cells are operated in a galvanostatic mode by means of multichannel Chroma ${ }^{\circledR} 63600$ electric loads (63610-80-20 and 63600-. 80-80) with remote sensing to avoid ohmic effects in source cables, capable of highspeed waveform generation suitable for EIS analysis. Instead, for specific diagnostics measurements and AST execution, an Autolab $^{\circledR}$ PGSTAT30 with FRA module is adopted.

Data acquisition system is based on National Instrument ${ }^{\circledR}$ DAQmx interface and a custom developed LabView ${ }^{\circledR}$ interface, integrating the abovementioned setup in a comprehensive platform.

macroSegmented-cell with RHE.-A $25 \mathrm{~cm}^{2}$ macro-segmented Fuel Cell (m-SFC or segmented-cell in the next) hardware ${ }^{24,25}$ is utilized in the experimental activity, permitting single cell performance analysis with an active localized control on four macroregions of the cell. Depicted in Fig. 1 A, it enables complete electrochemical characterization of each segment while limiting internal border effects, avoiding crosscurrents and reciprocal interference between segments; the limited invasiveness of the setup has been demonstrated in Refs. 24, 25. The flow-field geometry for both the anode and cathode is a triple serpentine channel. The channel is $1.0 \mathrm{~mm}$ wide and $0.9 \mathrm{~mm}$ deep, including a preheating section. The land is $1 \mathrm{~mm}$ wide. Both at anode and cathode, the flow plates are divided into four sections of active area: segment $1=5.832 \mathrm{~cm}^{2}$, segment $2=5.797 \mathrm{~cm}^{2}$, segment $3=7.652 \mathrm{~cm}^{2}$ and segment $4=$ $5.719 \mathrm{~cm}^{2}$. Segmentation cuts were realized on the ribs to prevent alterations in channel cross section. The gas flow configuration adopted was counter-flow: using this configuration, the segments 1 refers to the cathode inlet/anode outlet while segment 4 indicates the cathode outlet/anode inlet region. The segmented-cell reference operating protocol is galvanostatic: total current is imposed, which is controlled individually for each segment by the previously mentioned modular electronic load, aiming to maintain the four segments at the same voltage. This configuration permits to identify the instantaneous contribution of each segment to the overall current density in the cell while operating it as if the MEA was in standard single-cell hardware, i.e. limiting crosscurrents between consecutive segments. The segmented-cell was heated with cartridge heaters: the temperature was controlled, independently on each side, by a PID algorithm implemented in NI Labview ${ }^{\circledR}$.

Each segment of the setup is also provided with a localized reference hydrogen electrode (RHE) to provide a local mapping of the potentials for the individual electrodes. The innovative throughplane design adopted has been discussed in publications by Piela et al. $^{26}$ and by Brightman and Hinds in PEMFC ${ }^{27}$ and Rabissi in DMFC applications, ${ }^{24,28}$ to which the reader is pointed for a detailed description of the RHE setup. Since hydrogen for setting reference potential is encapsulated externally from the MEA, this setup has been identified as more proper for studying start-up/shut-down operations which require continuous gas feed modifications, avoiding potential drop effects and modifications to MEA structure.

Briefly, as shown in Fig. 1B, the salt bridge consists of a $10 \mathrm{~cm}$ Nafion ${ }^{\circledR}$ tubing (Permapure $^{\circledR}$, NJ, USA. Internal diameter of $0.6 \mathrm{~mm}$, 
(A)

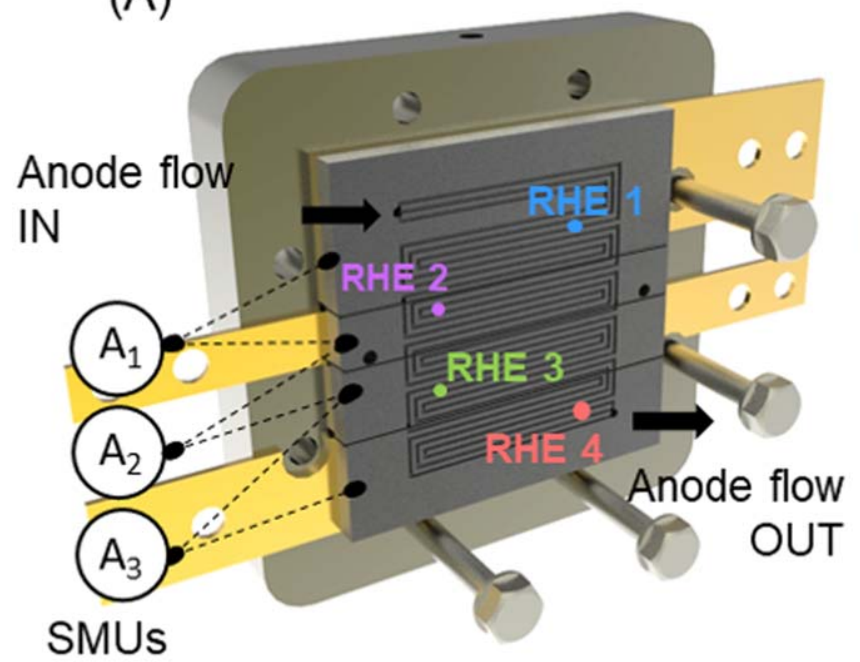

(B)

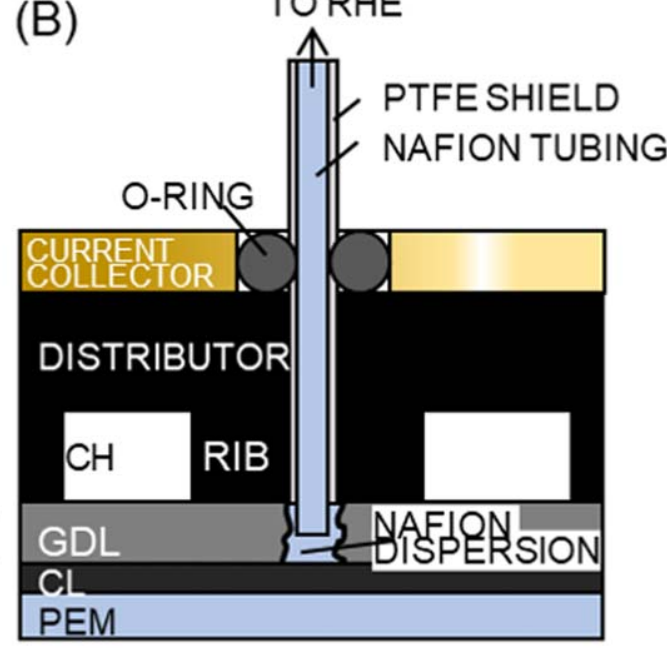

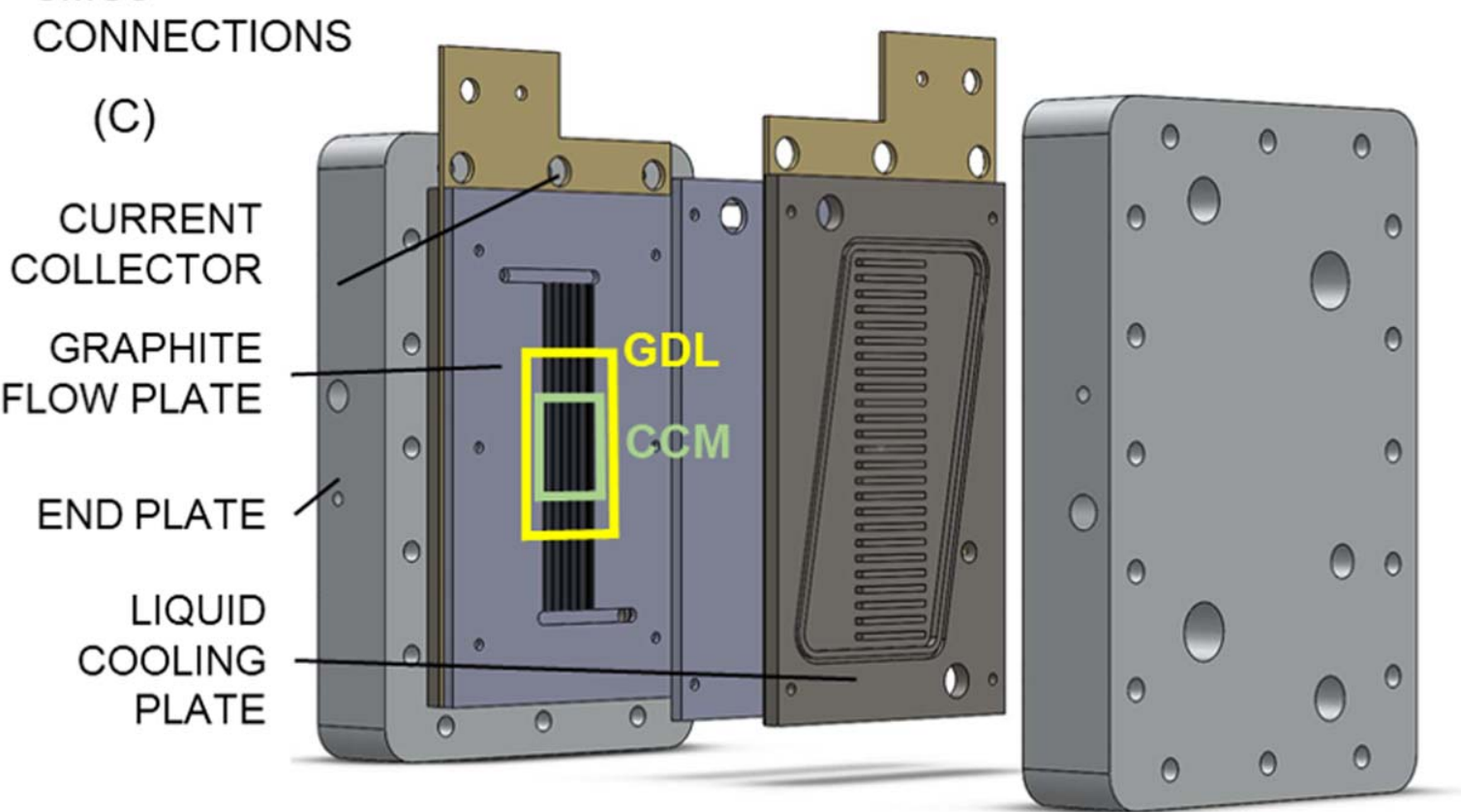

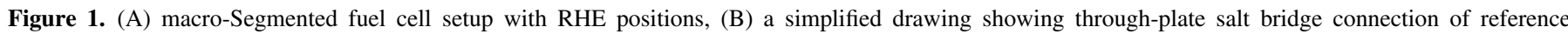
electrode, (C) Schematic diagram of the zero-gradient Fuel Cell hardware.

external diameter of $0.8 \mathrm{~mm}$ ) encapsulated in a PTFE shield. On one side the salt bridge crosses the cell end plates, current collectors and flow fields, which are accordingly perforated at the positions reported in Fig. 1A to permit a direct contact of the salt bridge with the GDL. To ensure a performing ionic contact towards the CL, small holes have been machined in the GDL $(\mathrm{d}=0.9 \mathrm{~mm})$ and filled with a solution of liquid Nafion ${ }^{\circledR}$ and isopropyl alcohol. A PEEK filament $(0.45 \mathrm{~mm}$ diameter $)$ is plugged in to improve mechanical performance, permitting an O-ring arrangement to prevent gas leakages. On the other side, salt bridge reaches a $0.5 \mathrm{M} \mathrm{H}_{2} \mathrm{SO}_{4}$ electrolyte filled vessel in which the hydrogen reference electrode (HydroFlex manufactured by Gaskatel ${ }^{\circledR}$ ) is immersed. To prevent tubing dehydration and maintain thus a good ion-conductive path, Nafion tubing is filled by same $0.5 \mathrm{M} \mathrm{H} \mathrm{H}_{2} \mathrm{SO}_{4}$ acid. Potential measurements with RHEs were performed at three different operating temperatures: $30^{\circ} \mathrm{C}, 40^{\circ} \mathrm{C}$ and $80^{\circ} \mathrm{C}$.

Moreover, the in-plane current exchanged between consecutive segments during an air start was also measured. In literature there are three common approaches for in-plane current measurements in fuel cells: shunt resistors, ${ }^{29,30}$ hall sensors ${ }^{31,32}$ and printed circuit boards. ${ }^{33,34}$
In the present work, localized currents have been measured through a novel technique based on high-precision source-measure units (SMU) modules (National Instrument ${ }^{\circledR}$ PXIe-4139) imposing $\Delta \mathrm{V}_{\text {segisegi+1 }}=0$ between two consecutive segments. This permits to measure the current flowing between insulated single segments. In our configuration, three units connected alternatively at anode or cathode side operate as current sources/sink to measure the currents contributions during start-up/shutdown operations.

The current density generated/consumed by each segment $j$ is recomputed according to Eq. 2, assuming that the sum of all contributions is equal to zero due to charge conservation:

$$
i_{\text {seg }, j}=\frac{I_{j}-I_{j-1}}{\text { Area }_{\text {seg }, j}}, \text { with } I_{0}=I_{4}=0
$$

where $i_{\text {seg, }}$ is the current density $\left[\mathrm{A} \mathrm{cm}^{-2}\right]$ generated/consumed by each segment, $I_{j}$ and $I_{j-1}$ are the currents $[A]$ flowing between two consecutive segments measured by SMU units, and Area $a_{\text {seg, }}\left[\mathrm{cm}^{2}\right]$ is the active area of the $j$ th segment. The use of SMUs guaranteed a high accuracy, fast responsiveness, and adaptability to different flow 
fields configurations. To characterize fast start-up/shut-down operation $(<1 \mathrm{~s})$, as required for automotive application, the acquisition time was set to $10 \mathrm{~ms}$. Current full scale was set at $3 \mathrm{~A}$, and current measurement resolution is $1 \mu \mathrm{A}$ while the accuracy is the $0.082 \%$ of the current value $+900 \mu \mathrm{A}$. Voltage full scale was set at $6 \mathrm{~V}$ instead and voltage measurement resolution is $1 \mu \mathrm{V}$ while the accuracy is the $0.02 \%$ of the voltage value $+300 \mu \mathrm{V}$.

Zero-gradient cell.-The work relies also on a novel zerogradient cell hardware, which has been appositely developed at Politecnico di Milano, to operate the MEA in homogeneous conditions over the cell area.

One of the most crucial characteristics is the pattern of the gas channels, as shown in Fig. 1C: a parallel flow design was chosen as it is the one that minimizes the pressure drops. Despite this type of flow field is not optimal for gas distribution and water management, these drawbacks have been overcome by the effects of the high stoichiometric ratios utilized (i.e. anode/cathode $=8 / 10$ ). The parallel channel design permitted to adopt high reactants stoichiometry to homogenize gas and water distribution. The configuration features small-channels ( 24 channels $0.4 \mathrm{~mm} \times 0.6 \mathrm{~mm}$ at cathode, 25 channels $0.3 \mathrm{~mm} \times 0.3 \mathrm{~mm}$ at anode $)$ and large-ribs $(0.25 \mathrm{~mm}$ at cathode, $0.55 \mathrm{~mm}$ at anode), with similar performance as observed for the JRC reference zero-gradient hardware, ${ }^{22,23}$ in order to homogenize the gas distribution over the active area of the CCM. While the total width of the channels $(20 \mathrm{~mm})$ was imposed by the desired active area, their length $(123.5 \mathrm{~mm}$ at cathode and $96 \mathrm{~mm}$ at anode) was chosen to be significantly longer than of the MEA in order to assure a complete preheating and flow development prior to the gas reaching the GDL. To ensure a uniform gas distribution in all the channels, two large manifolds, both at the inlet and outlet, were designed. The active area, of width $20 \mathrm{~mm}$ and length $50 \mathrm{~mm}$, is defined by two Mylar ${ }^{\circledR}$ sub-gaskets, one at the anode and one at the cathode side of the CCM. The GDL section is $30 \mathrm{~mm} \times 60 \mathrm{~mm}$, while the CCM section is $25 \mathrm{~mm} \times 55 \mathrm{~mm}$. This configuration was observed in the design phase to be the one maximizing performance.

A liquid-cooling system was adopted: it consists of a ThermoFischer ${ }^{\circledR}$ AC200 thermostatic bath and two heat exchanger plates, one at the anode and one at the cathode, designed to be mounted between the endplate and the current collector. Temperature distribution is recorded at both anode and cathode graphite-plate, near the active area.

Diagnostic protocols.-Polarization curve (also i-V curve in the following) is adopted to map the voltage response as a function of current density of the fuel cell and recorded in both reference conditions $\left(\mathrm{H}_{2} /\right.$ Air at anode and cathode respectively) as well as in pure oxygen feeding $\left(\mathrm{H}_{2} / \mathrm{O}_{2}\right.$ at anode and cathode respectively) to isolate mass transport resistance.

Reference polarization curve $\left(\mathrm{H}_{2} /\right.$ air $)$ is measured at $80{ }^{\circ} \mathrm{C}$ cell temperature at constant stoichiometry for current densities from $0.05 \mathrm{~A} \mathrm{~cm}^{-2}$ up to $1.5 \mathrm{~A} \mathrm{~cm}^{-2}$ for the segmented-cell and to $3 \mathrm{~A} \mathrm{~cm}^{-2}$ for the zero-gradient cell hardware. The minimum flow rate is set at $0.2 \mathrm{~A} \mathrm{~cm}^{-2}$ and $0.5 \mathrm{~A} \mathrm{~cm}^{-2}$ for single-cell and zerogradient cell respectively, i.e. for lower currents the test is performed at fixed flow rate. Gas is fed fully humidified with a stoichiometry of $2 / 4$ and 8/10 in segmented-cell setup and zero-gradient cell, at 250/ $230 \mathrm{kPa}$ backpressure for anode and cathode respectively. The only exception is for the ION POWER MEAs where the tests has been performed at ambient pressure due to RHE O-ring sealing pressure limitations.

Prior to recording a polarization curve, the MEAs were conditioned at $0.2 \mathrm{~A} \mathrm{~cm}^{-2}$ for $5 \mathrm{~min}$ under the operating conditions of the test, in agreement with EU Harmonized Test Protocols. ${ }^{35}$ The maximum current was set avoiding voltage to decrease below $0.3 \mathrm{~V}$. Moreover, only the current descending points are used for the polarization curve, discarding the initial transient of each current density step.

$\mathrm{H}_{2} / \mathrm{O}_{2}$ polarization curve is performed at the same operating conditions of air polarization curve. In order to maintain unvaried pressure drop in the channels with respect to the reference case, oxygen mass flow was kept constant with respect to the air test, leading to very high stoichiometry at cathode (up to 19 in zerogradient cell). In case mass activity is evaluated, 5 low-current points are added at the end of polarization ranging from 0.020 to $0.001 \mathrm{~A} \mathrm{~cm}^{-2}$ and each held for $5 \mathrm{~min}$.

During polarization curves measurement, Electrochemical Impedance Spectroscopy (EIS) is measured at $0.8,0.4$ and $0.1 \mathrm{~A} \mathrm{~cm}^{-2}$ and $0.4,1.0$, $2.0,3.0 \mathrm{~A} \mathrm{~cm}^{-2}$ in segmented-cell and zero-gradient setups, with 50 logarithmically spaced frequencies in a range from $0.07 \mathrm{~Hz}$ to $20 \mathrm{kHz}$. EIS was performed in galvanostatic mode with the current oscillation set to obtain a voltage oscillation lower than $10 \mathrm{mV}$ to respect the linearity condition. As detailed in Ref. 25, in order to avoid any reciprocal interference between consecutive segments, accurate synchronous sinusoidal oscillation of the current density for all the segments is guaranteed. Measurement consistency is verified by a retrospective use of KramersKronig transforms: ${ }^{36}$ the impedance values that do not satisfy such relations are discarded.

Cyclic voltammetry has been adopted to quantitatively estimate catalyst layer electrochemical active surface area (ECSA) on both the setups described in Figs. 1A and 1C.

On the segmented-cell setup, current associated to each segment is independently measured using four $\mathrm{NI}^{\circledR}$ SMUs PXIe-4139, while, in the case of the zero-gradient hardware, an Autolab ${ }^{\circledR}$ PGSTAT30 potentiostat is adopted. Cyclic voltammograms were collected between $0.07 \mathrm{~V}$ and $0.6 \mathrm{~V}$ vs RHE at a scan rate of $50 \mathrm{mV} \mathrm{s}^{-1}$ at $30{ }^{\circ} \mathrm{C}$. The ECSA value was estimated by $\mathrm{H}$-desorption charge using a specific charge $\sigma_{m}$ of $210 \mu \mathrm{C} \mathrm{cm}^{-2}$. Defining the potential at which the current has a minimum in the positive half of the chart as $E_{d l}$, the scan rate $\left[\mathrm{mV} \mathrm{s}^{-1}\right]$ as $S c$ and the Pt loading as $L_{P t}\left[\mathrm{mg}_{\mathrm{Pt}} \mathrm{cm}^{-2}\right]$ :

$$
E C S A=\frac{\int_{O C V}^{E_{d l}} i d V}{\sigma_{m} L_{P t} S c}\left[m^{2} g_{P t}^{-1}\right]
$$

A linear sweep voltammetry (LSV) was performed under $\mathrm{H}_{2} / \mathrm{N}_{2}$ gas feed to study the reduction of $\mathrm{Pt}$ oxides covering the catalyst. LSV was performed from $1.0 \mathrm{~V}$ to $0.08 \mathrm{~V}$ vs RHE at a scan rate of $50 \mathrm{mV} \mathrm{s}^{-1}$. For the voltage cycling and linear sweep tests were conducted under $\mathrm{H}_{2} / \mathrm{N}_{2}$ (anode/cathode) at $0.06 / 0.60 \mathrm{Nl} \mathrm{min}{ }^{-1}, 100$ $\mathrm{kPa}_{\mathrm{abs}}, 30{ }^{\circ} \mathrm{C} 100 \% \mathrm{RH}$.

Catalyst activity measurement requires a purely kinetic current due to the ORR. For this reason, MEAs are tested using $\mathrm{H}_{2} / \mathrm{O}_{2}$ as reactants to minimize mass transport resistances. Moreover, as done by Gasteiger et al. ${ }^{37}$ and suggested by DOE protocols, ${ }^{38}$ activities are evaluated at $0.9 \mathrm{~V}$ : here the overpotential losses, due to resistance, mass transport, current distribution and effects of oxygen utilization are expected to be negligible.

Catalyst mass activity $i_{m,(0.9 \mathrm{~V})}$ is evaluated as:

$$
i_{m(0.9 V)}=\frac{i_{e f f(0.9 V)}}{L_{p t}}\left[A m_{P t}^{-1}\right]
$$

where $i_{\text {eff }(0.9} V$ ) is the effective current density (corrected for $\mathrm{H}_{2}$-crossover contribution) at $0.9 \mathrm{~V}$ (iR-free) obtained from a linear regression of fully corrected polarization curve, while $L_{p t}$ is the platinum catalyst loading. An experimental Tafel slope value of $70 \mathrm{mV} /$ decade was verified for consistency with Refs. 39, 40 at $353.15 \mathrm{~K}$.

The limiting current density is the maximum current that can be produced by a cell as the concentration of reactant $\mathrm{O}_{2}$ at the electrode working surface approaches zero ${ }^{41,42}$ and permit estimation of oxygen mass transport resistance $R_{T}$. In limiting current operation, when concentration of oxygen at catalyst surface approaches zero, the mass transport resistance $R_{T}$ can be estimated as:

$$
R_{T}=4 F \frac{x_{O_{2}, \text { in }}^{d r y}}{i_{\text {lim }}} \frac{p-p_{w}}{R T}
$$

where $p$ is the total gas pressure, $p_{w}$ is the water vapor pressure, dependent only on $\mathrm{T}$ and $x^{d r y} \mathrm{O}_{2}$,in is oxygen molar fraction at inlet. 
Table I. US Department of Energy (DOE) Accelerated Stress tests protocols.

Catalyst Support AST

Triangle square wave

$1.5 \mathrm{~V} / 1.0 \mathrm{~V}$ vs RHE

$0.5 \mathrm{~V} \mathrm{~s}^{-1}$

$2 \mathrm{~s}$

$80{ }^{\circ} \mathrm{C}\left(30{ }^{\circ} \mathrm{C}\right.$ where indicated $)$

$100 \%$

Atmospheric

0.06/0.06 Nl min ${ }^{-1}$
Electrocatalyst AST

Square wave cycle

$0.6 \mathrm{~V} / 0.95 \mathrm{~V}$ vs RHE

$0.7 \mathrm{~V} \mathrm{~s}^{-1}$

$6 \mathrm{~s}$

$80{ }^{\circ} \mathrm{C}$

$100 \%$

Atmospheric

$0.06 / 0.06 \mathrm{Nl} \mathrm{min}-1$

Table II. Un-mitigated start-up/shut-down protocol at $80{ }^{\circ} \mathrm{C}, 100 \% \mathrm{RH}$ and ambient pressure.

\begin{tabular}{lll} 
Step & Name & Description \\
\hline$\# 1$ & Operation & $600 \mathrm{~s}:$ galvanostatic holding at $0.4 \mathrm{~A} \mathrm{~cm}$ \\
$\# 2$ & Refresh & $300 \mathrm{~s}$ (since cathode potential decreases below $100 \mathrm{mV}$ ): $\mathrm{H}_{2} / \mathrm{cathode} \mathrm{closed}^{-2}$ \\
$\# 3$ & Standby & $60 \mathrm{~s}:$ OCV in $\mathrm{H}_{2} /$ Air \\
$\# 4$ & Start-up (SU) & Allow hydrogen flow an anode and wait $60 \mathrm{~s}$ \\
$\# 5$ & Shut-down (SD) & Allow air flow at anode and wait $60 \mathrm{~s}$
\end{tabular}

The total resistance is the outcome of different contributions. In this work, pressure is varied to investigate the separation between a pressure-dependent component $\left(R_{T, P D}\right)$, related to intermolecular gas diffusion, and a pressure-independent component $\left(R_{T, P I}\right)$, i.e. Knudsen diffusion and transport through ionomer/liquid water layers. At the same time, $R_{T}$ could be seen as the summation of single-layer resistances. Since it is the pore size that determines the gas diffusion type, molecular phenomena are dominant in the GDL and flow-fields, while Knudsen diffusion dominates in the MPL and in the catalyst layer, where also ionomer-related resistances count. Following the procedure proposed by Baker et al. ${ }^{41,42}$, limiting current should be related to the oxygen fraction by a zero-crossing linear correlation at each pressure condition, in accordance with Eq. 5. Once the average ratio at each $p$ is found, this value is used for computing total oxygen mass transport resistance.

Thereafter, pressure independent $\left(R_{T, P I}\right)$ and dependent $\left(R_{T, P D}\right)$ components are disentangled thanks to a linear regression vs the absolute pressure, using the approximation described by Greszler et al.: ${ }^{43}$

$$
R_{T}=R_{T, P D}+R_{T, P I}=R_{C H}+R_{D M}+R_{M P L}+\frac{R_{O_{2}}^{P t}}{f_{P t}}
$$

where $R_{T}$ is the total oxygen resistance, $R_{T, P D}$ and $R_{T, P I}$ are the pressure-dependent and pressure-independent terms of total oxygen mass-transport resistance, $R_{C H}, R_{D M}$, and $R_{M P L}$ denotes the transport resistances in the channel, diffusion media, and MPL, respectively. $R_{O 2}{ }^{P t}$ is the local transport resistance on the surface of the platinum while $f_{P t}$ denotes the roughness factor in $\mathrm{cm}_{2}{ }^{\mathrm{Pt}} / \mathrm{cm}_{2}$.

The tested average absolute pressures for cathode side are $210 \mathrm{kPa}$, $310 \mathrm{kPa}$ and $360 \mathrm{kPa}$ for the segmented-cell and $150 \mathrm{kPa}, 250 \mathrm{kPa}$ and $350 \mathrm{kPa}$ for the zero-gradient hardware (except tests for ION POWER MEA described below, due to RHE system pressure limitations where tested pressures are $115 / 150 / 200 \mathrm{kPa}$ ). Temperature and relative humidity were kept at $80{ }^{\circ} \mathrm{C}$ and $100 \%$, respectively. This test is carried out at the fixed flows of $0.5 \mathrm{Nl} \mathrm{min}-1$ and $4 \mathrm{Nl} \mathrm{min}-1$ at anode and cathode, respectively. Dilutions of $1 \%, 2 \%$ and $3 \%$ of $\mathrm{O}_{2}$ in inert $\mathrm{N}_{2}$ are evaluated; note that flow rates are such high that the influence of stoichiometric variations on results is assumed negligible. The limiting current density is evaluated by means of Autolab ${ }^{\circledR}$ PGSTAT30 with booster $20 \mathrm{~A}$, averaging the current in the low voltage region at $0.3 \mathrm{~V}, 0.2 \mathrm{~V}$ and $0.1 \mathrm{~V}$. Each point is held for $180 \mathrm{~s}$.

Aging protocols.-In the following, the aging protocols adopted in the work are described.

Accelerated stress tests.-Catalyst layer stability has been separately evaluated for support and electrocatalyst by means of AST protocols developed by DoE and reported in DoE 2017 Fuel Cell Program. ${ }^{38}$ In catalyst support AST corrosion of the carbon support of the catalyst layer is enhanced while reducing as much as possible the electrocatalyst degradation through fast high-voltage cycling. Instead, electrocatalyst AST promote consecutive oxidations and reductions of platinum catalyst by means of a lower voltage square wave. Specifications, as suggested by DoE, are summarized in Table I:

Start-up/shut-down protocols.-To reproduce start-up/shut-down cycle both with and without mitigations, two protocols have been appositely developed to investigate degradation associated with such operation. These protocols are named "un-mitigated start-up/shutdown" and "mitigated start-up/shut-down" and described in Tables II and III. Un-mitigated SU/SD operation is summarized in Table II.

After galvanostatic operation (\#1), performed to allow MEA rehydration and measure performance, a refresh procedure (\#2) is

Table III. Mitigated start-up/shut-down protocol at $30{ }^{\circ} \mathrm{C}, 100 \% \mathrm{RH}$ and ambient pressure.

\begin{tabular}{lll} 
Step & Name & Description/repetitions \\
\hline$\# 1$ & Refresh & $300 \mathrm{~s}$ (since cathode potential decreases below $100 \mathrm{mV}$ ): $\mathrm{H}_{2} / \mathrm{N}_{2}$ \\
$\# 2$ & Mitigated shut-down (SD) & $120 \mathrm{~s}:$ Air/ $\mathrm{N}_{2}$ \\
$\# 3$ & & $120 \mathrm{~s}:$ Air/Air \\
$\# 4$ & Real start-up (SU) or $\mathrm{H}_{2} /$ air front & $120 \mathrm{~s}:$ OCV in Air/ $\mathrm{H}_{2}$ \\
Repeat \#1 - \#4 every $660 \mathrm{~s}$. &
\end{tabular}


applied to prevent any influence of the eventual catalyst surface oxidation: the flux at cathode is interrupted and the voltage is let decrease thanks to $\mathrm{H}_{2}$ crossover from the anode, promoting cathode catalyst oxides reduction. After the cell voltage decreases to a value as low as $100 \mathrm{mV}$, a condition that is held for $5 \mathrm{~min}$, a sequence of SU/SD cycles (\#3-\#5) is performed. $\mathrm{A} \mathrm{H}_{2}$ /air OCV condition (\#3) is held for $60 \mathrm{~s}$ to simulate post-operation transient, then five in-a-row shut-down (\#4) and start-up (\#5) transients are performed, implemented as an air flow at anode followed by the $\mathrm{H}_{2}$ flow. The protocol was performed at $80{ }^{\circ} \mathrm{C}$ with fully humidified gases both at anode and cathode side and at ambient pressure. The anode fluxes were set to $\mathrm{N}_{\mathrm{H} 2 / \mathrm{Air}}=0.05 \mathrm{Nl} \mathrm{m^{-1 }}$ and at the cathode $\mathrm{N}_{\mathrm{Air}}=0.2 \mathrm{Nl} \mathrm{m^{-1 }}$.

A full diagnostic protocol, as described above, is periodically performed during start-up/shut-down protocol cycling. EoT (end-oftest) was chosen considering a minimum performance of $0.3 \mathrm{~V}$ during galvanostatic operation at $0.4 \mathrm{~A} \mathrm{~cm}^{-2}$.

Consistently to the protocol described in previous section, a modified SU/SD protocol has been also developed to simulate the execution of start-up/shut-down operation in presence of mitigation strategies as in state-of-the-art automotive systems. To goal is to reproduce in single-cell, through a fast and repeatable protocol, the long-stop and the subsequent $\mathrm{H}_{2}$ /air front at the restart of the operation as it occurs in the stack testing. The mitigated SU/SD protocol is described in Table III.

First, the shutdown and the long stop of the operation are mimicked. Starting from $\mathrm{H}_{2}$ /air $\mathrm{OCV}, \mathrm{N}_{2}$ is fluxed at cathode side for $300 \mathrm{~s}$, during which cathode potential decreases till approximately $100 \mathrm{mV}$ (\#1). After the purging of the oxidant by the inert, air is fluxed for $120 \mathrm{~s}$ through the anode (\#2). Cell voltage immediately drops further, till $0 \mathrm{~V}$. Same voltage is kept when air is introduced into the cathode (\#3): the post-long stop air/air condition is finally reached and high cathodic potentials are avoided during the shutdown transient which is thus defined as mitigated. This purge operation with nitrogen permits to reproduce the shut-down quickly and in a controlled manner. Then, the restart of the operation is simulated. After $120 \mathrm{~s}, \mathrm{a} \mathrm{H}_{2}$ /air front is finally generated at anode side causing the start-up (\#4). After $120 \mathrm{~s}$ again, the described procedure is repeated (\#5).

The start-up operation was performed following the specifications of the ID-FAST European project durability test program, according to indications provided by car manufactures. The flux of hydrogen during start-up must be $1 \mathrm{~A} \mathrm{~cm}^{-2}$ equivalent. Using a 25

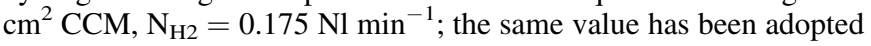
for the air flux at anode side. Applying this specification also to the

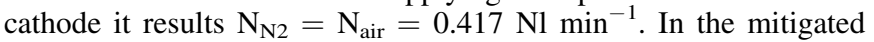
protocol the galvanostatic operation (i.e. step 1 in Table II) was not considered and the EoT criterion was set at 200 cycles.

Ex-situ analysis.-Ex-situ analyses were performed on pristine and aged JMFC MEAs to support degradation investigation as described in the following:

Scanning and transmission electron microscopy.-Samples were cut from the fresh MEA and from both MEAs aged under mitigated SU/SD degradation test in segmented-cell and under start-up AST in zero-gradient cell. For the MEA aged under mitigated SU/SD, crosssections were taken at different positions of the surface area: air inlet, middle and air outlet. After embedding in epoxy resin, crosssection samples were prepared by mechanical polishing until mirrorlike surface and then observed by scanning electron microscopy (SEM). Then thin MEA cross-sections $(90 \mathrm{~nm}$ ) were cut using a LEICA ultramicrotome and analyzed by transmission electron microscopy (TEM).

SEM and TEM observations were respectively performed using a ZEISS-MERLIN field emission gun (FEG) microscope and a FEITitan Ultimate microscope equipped with a $\mathrm{Cs}$ aberration probe corrector. For each sample, histograms of Pt particle size distribution were built from TEM images recorded in high-angle annular darkfield / scanning transmission electron microscopy (HAADF/STEM) mode. For this, Pt nanoparticle sizes were measured automatically on high magnification images (pixel size of $0.03 \mathrm{~nm}$ ) using the ImageJ analysis software (http://rsbweb.nih.gov/ij/download.html). A specific procedure was adopted: ${ }^{44}$ (1) grey level threshold was applied and brightness and contrast were corrected, no other operations or filters were used; (2) touching particles were not elaborated, rather all particles were recorded and those that had an aspect ratio (AR) more than 1.25 were excluded from fitting; (3) the area-equivalent average diameters of all valid particles were used to fit log-normal particle size distributions.

To be reliable, the automatic counting must consider a large number of particles. For this analysis, total particles analyzed are more than 500. The number of particles that was counted respectively for each sample was: segmented-cell inlet (SEG 1) $=922$; segmented-cell middle (SEG 2/3) = 1241; segmented-cell outlet $($ SEG 4$)=1179 ;$ start-up AST $=685$.

$X$-ray photoelectron spectroscopy.-XPS measurements have been performed using a ESCALAB 250 ultra-high vacuum (UHV) facility from Thermo Scientific. The base pressure in the analysis chamber was $10^{-9}$ mbar. As X-ray source (Thermo Scientific XR4 operated at $300 \mathrm{~W}$ ) $\mathrm{Al} \mathrm{K \alpha}$ radiation was used. The kinetic energy of the electrons was measured with a hemispherical electron energy analyzer.

The concentrations of elements (given in atomic percent, at \%) are calculated using sensitivity factors provided by Thermo Scientific. For the analysis of the CL/MPL interface two layers were disassembled by pulling the GDL with the MPL off the catalyst coated membrane.

Electronic Supplementary Information (ESI) including experimental datasets are available at DOI: 10.5281/zenodo.4695961, under a CC-BY-4.0 license.

\section{Results and Discussion}

The process of reverse-current mechanism is initially elucidated through mapping of local potential by means of reference hydrogen electrode arrays at the anode and cathode.

During reverse-current mechanism, while hydrogen is progressively flowing in the anode side, the domain is ideally divided into two parts. In the anode region occupied by hydrogen, the MEA operates as a fuel cell with hydrogen oxidation reaction (HOR) and oxygen reduction reaction (ORR) at anode and cathode respectively: this region is generally named as active region. The remaining region, where anode is filled with air, is instead defined as passive region, where ORR takes place at the anode while oxidation reactions, such as carbon oxidation reaction (COR) and oxygen evolution reaction (OER), occur at the cathode. The simultaneous current exchanged between the active and passive regions causes a reverse proton flow in the air/air and the hydrogen/air regions, leading to a circular current flow in the cell. The fuel-filled regions, which operate normally as a power supply, are expected to polarize the remaining part. This description, which figures the cell as divided in two halves and in steady-state conditions, is not thorough: the cell voltage, and thus both metal and electrolyte potentials, are not constant but progressively change during the transients. Process lasts as the two gases at the anode co-exist.

First, the start-up process is analyzed, measuring anode and cathode local potentials which are depicted in Figs. 2A and 2C for both the MEAs tested in this work. Starting from air/air condition, both the anode and cathode electrodes are close to the equilibrium potential (about $1.05 \mathrm{~V}$ vs RHE), resulting in cell voltage near $0 \mathrm{~V}$. When anode gas is switched from air to hydrogen, the cell voltage (represented with black line in Fig. 2), increases rapidly. The active region at anode inlet/cathode outlet (represented with red lines in Figs. 2A-2C) operates as a normal fuel cell, with cathode potential at $0.7-0.8 \mathrm{~V}$ vs RHE. Instead, passive region at anode outlet/cathode inlet (represented with blue lines in Figs. 2A-2C) operates under air/ air: the anode electrode runs in ORR mode, while cathode reaches 

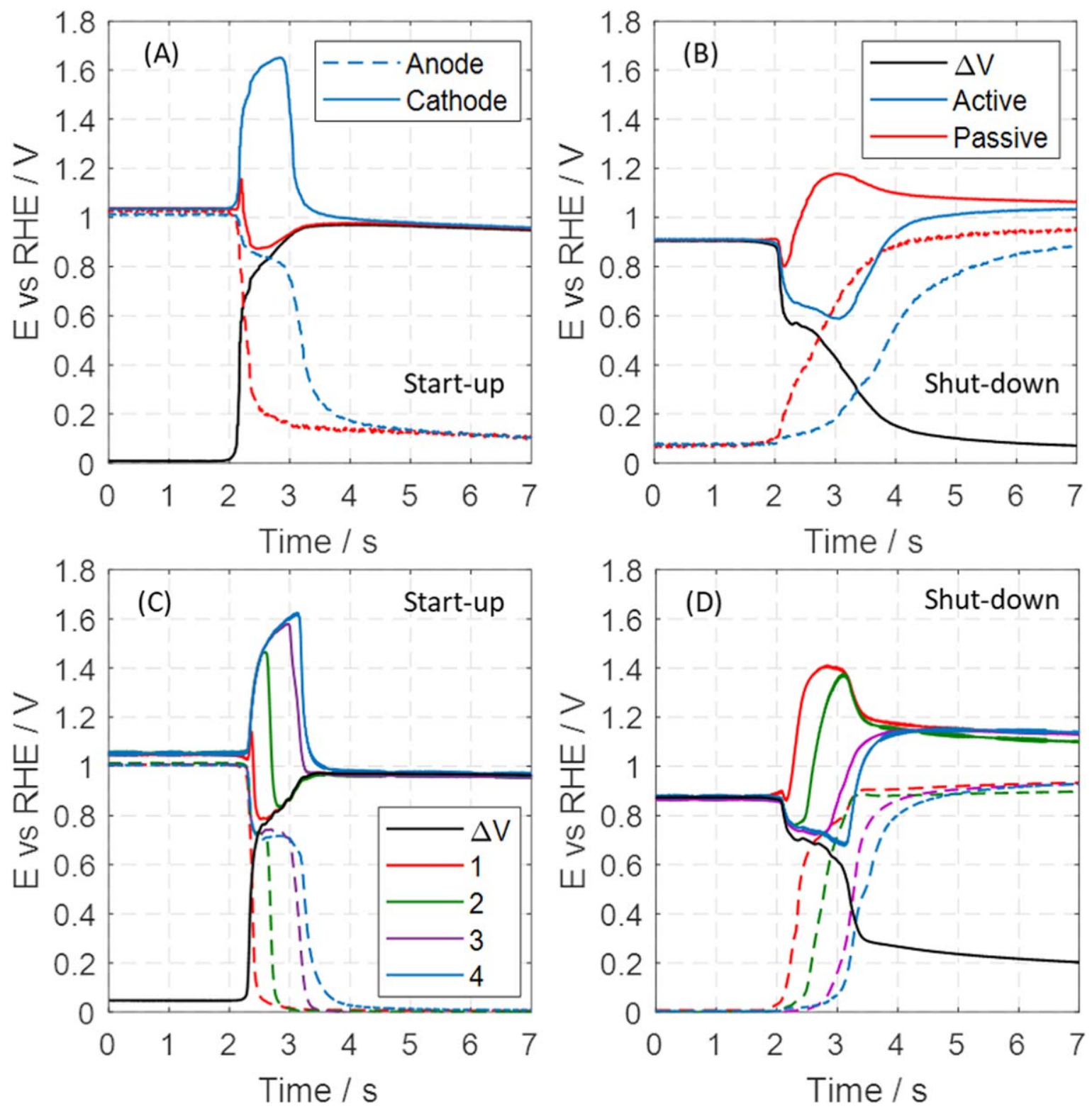

Figure 2. Local potential profiles collected with reference hydrogen electrodes (RHEs) for (A)-(B) ION POWER and (C)-(D) JMFC MEAs during (A)-(C)

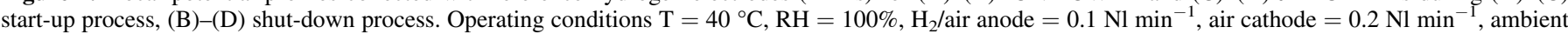
pressure. The position of RHE depicted in legend in figure c, are referred to: 1- Segment 1 (cathode inlet/anode outlet), 2- Segment 2, 3- Segment 3, 4- Segment 4 (cathode outlet/anode inlet). Dashed lines are anode electrode potentials and solid lines cathode electrode potentials, both measured with RHEs. Solid black line is the cell voltage.

high potential near $1.5 / 1.6 \mathrm{~V}$ vs RHE, boosting COR/OER. At the end of the start-up process the whole anode compartment is filled with hydrogen: in Open Circuit Voltage (OCV) near 0.9-0.95 V, the anode electrode is close to equilibrium of $0 \mathrm{~V}$ vs RHE and cathodic potential is around $0.9 \mathrm{~V}$.

The shut-down process is symmetric to start-up but leads to different effects, as visible in Figs. 2B and 2D for each MEA tested in this work. First, the duration of start-up is lower than shut-down, in which it seems to double. Active and passive regions are inverted with respect to start-up operation, and the last reaches a lower peak potential, around 1.2-1.4 V vs RHE. As the air front flows through anode, the cell voltage drops from OCV (around $0.9 \mathrm{~V}$ vs RHE) to $0 \mathrm{~V}$, but with a slower dynamic than in the case of start-up. In part, the effect was due to the lower diffusion of oxygen with respect to the hydrogen in the start-up operation. A more detailed discussion of these aspects is described in Refs. 45-47.
Degradation under un-mitigated start-up/shut-down protocol. - The aim of the work presented in this section is to clarify and quantify the degradation caused by abovementioned SU/SD operation, in absence of any mitigation strategy. The attention is primarily focused on catalyst layer support failure which is known to be the most relevant issue related to SU/SD. Hence, as first step of the work, the aging effect driven by 1000 cycles of the carbon support AST protocol are compared to those given by 100 cycles of start-up/shut-down processes. Figures $3 \mathrm{~A}$ and $3 \mathrm{~B}$ compare air and pure oxygen polarization curves of aged MEAs. Characterization was performed at BoT, 500 and 1000 cycles of AST, while unmitigated SU/SD operations were analyzed after 60 and 100 cycles.

Polarization curves at 60 and 100 SU/SD are respectively in good agreement, both in oxygen and air, with 500 and 1000 cycles of support AST, indicating a factor of 10 in terms of cycles. Comparing instead the time for testing, the duration of the sequence of start-up 

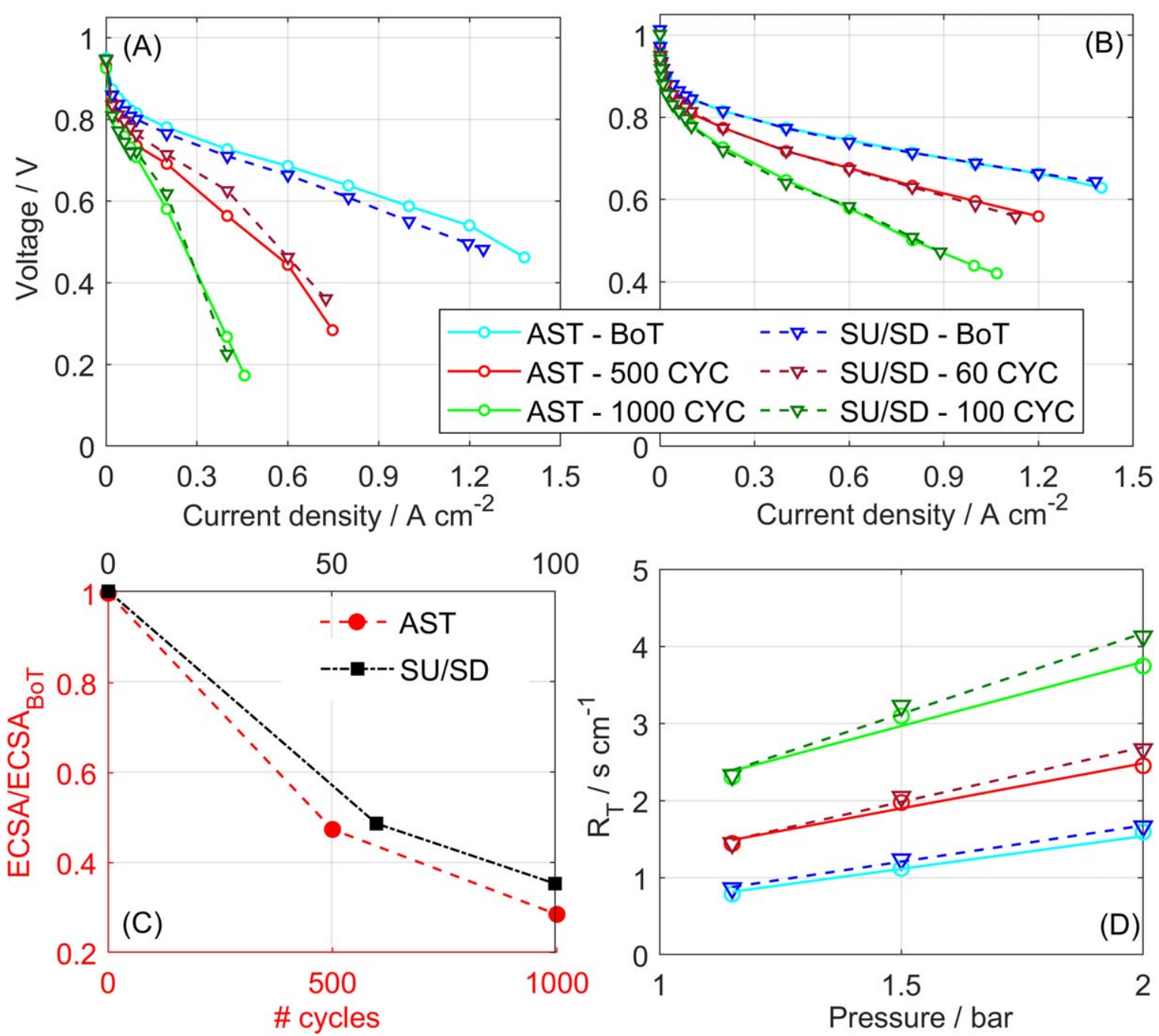

Figure 3. Comparison of degradation, on ION POWER MEA, after 1000 cycles of DoE catalyst support AST and 100 cycles of un-mitigated SU/SD in $25 \mathrm{~cm}^{2}$ single-cell: (A) air and (B) pure oxygen $\mathrm{i}-\mathrm{V}$ curves evaluated at, $\mathrm{T}=80^{\circ} \mathrm{C}, \mathrm{RH}=100 \%, \mathrm{P}=$ ambient, stoich. An/Ca $=2 / 4,(\mathrm{C}) \mathrm{Relative}$ change in ECSA (normalized to the ECSA at BoT) vs the number of cycles, conditions: $\mathrm{T}=30{ }^{\circ} \mathrm{C}, \mathrm{RH}=100 \%, \mathrm{P}=$ ambient, and flow rates of $0.06 \mathrm{NL}$ min- 1 for $\mathrm{H}_{2} / \mathrm{N}_{2}$ (anode/ cathode), (D) oxygen mass transport resistance measured at $\mathrm{P}=115 / 150 / 200 \mathrm{kPa}_{\text {(abs) }}$ and three oxygen concentration $\left(\mathrm{X}_{\mathrm{O} 2 \mathrm{dry}}=1 / 2 / 3 \%\right)$.

and shut-down is $120 \mathrm{~s}$, while the duration of an AST cycle is $2 \mathrm{~s}$. Considering the factor that makes 10 cycle of AST representative of the actual process, the AST accelerates the real ageing by a 6 factor. This consistency of performance fading of support AST with SU/SD operation indicates that the main aging mechanism found in unmitigated SU/SD is indeed corrosion of carbon support, in agreement with the literature findings. ${ }^{6}$ Degradation of carbon support is known to collapse the structure of cathode catalyst layer: both porosity and tortuosity of the carbon texture are expected to progressively increase gas transport resistances, while hindering triple phase boundary of the electrode by detaching and thus isolating platinum nanoparticles. ${ }^{9}$ To confirm this, performance evolution was investigated by electrochemical measurements to clarify the different contributions expected to be caused by carbon corrosion mechanism.

The evolution of ECSA of support AST is consistent with that of SU/SD operation as visible in Fig. 3C, which is shown to be halved after 500/60 cycles of support AST and SU/SD protocol respectively, and further reduced below $40 \%$ at EoT. Mass activity evolution, evaluated as described previously, is reported in Table IV to enable comparison of the decrease of platinum utilization for the two protocols, showing a significant extent and a sensible consistency. Indeed, at 1000/100 cycles of support AST and SU/SD protocol respectively, mass activity is only the $39 \%$ and the $30 \%$ of the initial

\begin{tabular}{|c|c|c|c|}
\hline \multicolumn{2}{|c|}{ Support AST } & \multicolumn{2}{|c|}{ SU/SD } \\
\hline Cycle & $\begin{array}{c}\text { Mass activity } \\
{\left[\mathrm{A} / \mathrm{mg}_{P t}^{-1}\right]}\end{array}$ & $\begin{array}{c}\text { cycle } \\
{[-]}\end{array}$ & $\begin{array}{c}\text { Mass activity } \\
{\left[\mathrm{A} / \mathrm{mg}_{P t}^{-1}\right]}\end{array}$ \\
\hline BoT & 0.064 & BoT & 0.070 \\
\hline 500 & 0.032 & 60 & 0.033 \\
\hline 1000 & 0.025 & 100 & 0.021 \\
\hline
\end{tabular}

value, confirming SU/SD operation to dramatically impact on cathode electrode. The variation of mass activity shows good consistency with ECSA loss and is larger in the initial part of the test (500/60 cycles of support AST and SU/SD protocol respectively), with a reduction of almost 50\% from BoT. This suggests that the largest loss of platinum occurs in the first stage.

Mass transport resistance is plotted as a function of pressure and is depicted in Fig. 3D, showing again strong consistency between SU/SD and support AST. Only minor differences of slopes emerge, related to the pressure-related term of Eq. 6: a slighter larger growth of $R_{T}$ for SU/SD operation is highlighted. 

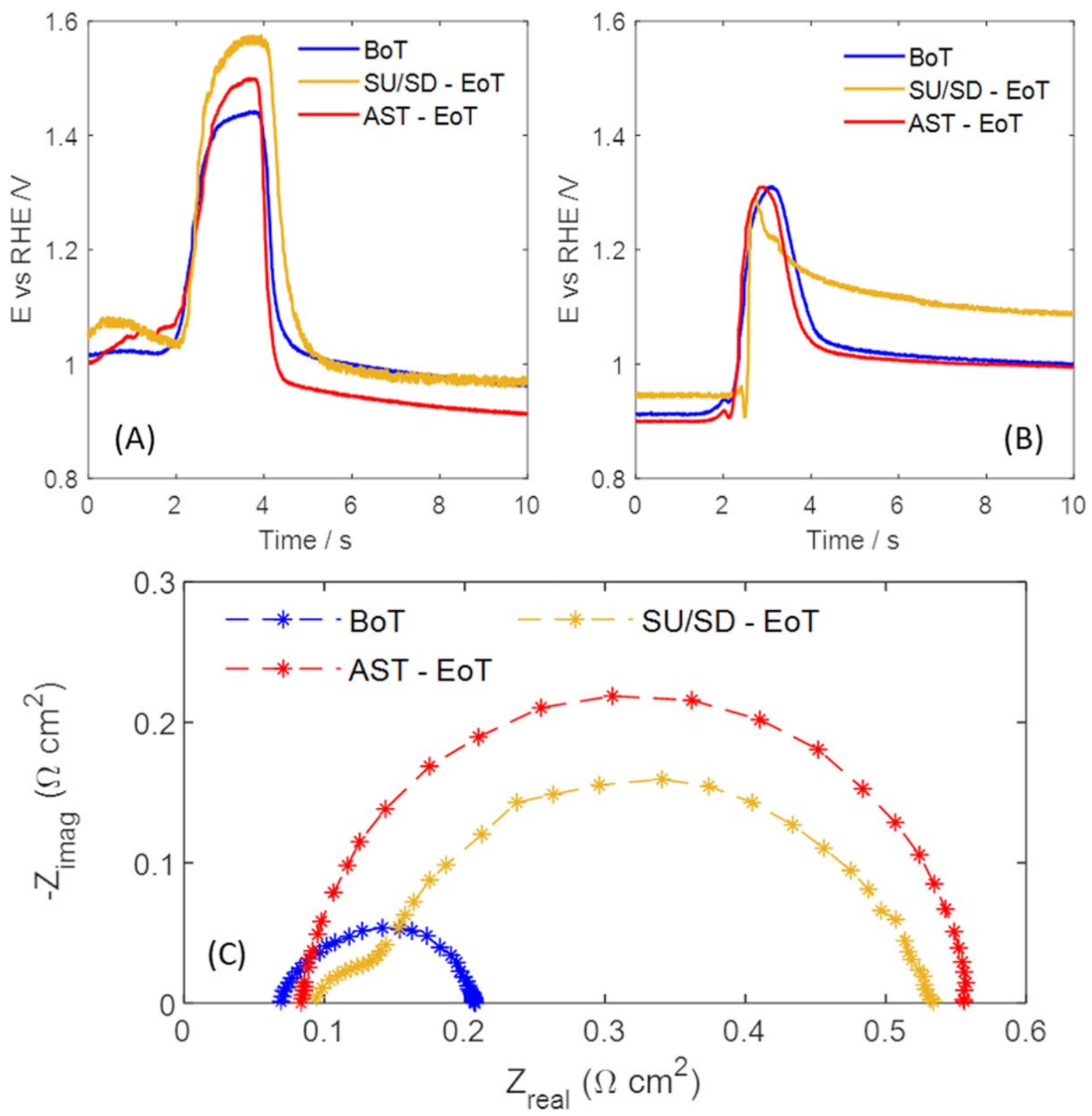

Figure 4. Variations of local potentials, recorded by RHEs at BoT and EoT of un-mitigated SU/SD and catalyst support AST on ION POWER MEA, (A) at cathode inlet during start-up, (B) at cathode outlet during shut-down. (C) Nyquist plot recorded in $\mathrm{H}_{2} / \mathrm{O}_{2}$ polarization curve at $0.4 \mathrm{~A} \mathrm{~cm}^{-2}$ at BoT and EoT for unmitigated start-up/shut-down and AST protocols, conditions: $\mathrm{T}=80{ }^{\circ} \mathrm{C}, \mathrm{RH}=100 \%, \mathrm{P}=$ ambient.

This effect could be attributed to heterogeneity of degradation during SU/SD operation, as observed by Cheng et al., ${ }^{48}$ that are absent or very limited in the accelerated stress test. To further investigate this aspect, three consecutives SU/SD cycles were performed during catalyst support AST as a diagnostic tool and the local potentials collected by means of RHEs. These profiles were compared with those recorded during un-mitigated SU/SD. Potential profiles at cathode inlet (during start-up) and at cathode outlet (during shut-down) are reported in Figs. 4A and 4B.

Already at the beginning of life, it is visible from the local potential that the cathode electrode is stressed differently during the start-up operation compared to shut-down. At BoT, the passive zone of the cathode during the start-up (opposite to anode outlet) reaches a maximum voltage of $1.4 \mathrm{~V}$. Conversely, the passive zone of the electrode during the shut-down (opposite to anode inlet) reaches a maximum potential of $1.3 \mathrm{~V}$. While the duration of the test remains similar in the cases, i.e. $2.2 \mathrm{~s}$, the potential transient over $1.2 \mathrm{~V}$ vs RHE is longer in the case of the start-up (1.63 s) with respect to the shutdown $(1.08 \mathrm{~s})$. The start-up/shut-down duration is usually described by the residence time under the plug-flow assumption. ${ }^{49,50}$ This parameter represents the time required for the complete replacement of the gas in the anode compartment during the $\mathrm{H}_{2} /$ air front. $\mathrm{Yu}$ et al. has shown that the degradation rate is linearly correlated to the theoretical residence time. In this work, it is calculated as in Eq. 7, such as the ratio of the volume to be replaced of flow-field $\left(V^{F F}=1.46 \mathrm{~cm}^{3}\right)$ and GDL $\left(V^{G D L} \sim 0.28 \mathrm{~cm}^{3}\right)$ to the humidified gas flow rate, at a given temperature $(\mathrm{T}), \mathrm{RH}$ and operating pressure.

$$
t_{R e s}=\frac{V^{F F}+V^{G D L}}{\dot{V}_{T, p, R H}^{\text {wet }}}=\frac{V^{F F}+V^{G D L}}{\dot{V}_{0}^{d r y} \frac{p_{0}}{p_{g a s}} \frac{T}{T_{0}}}
$$

Where, $\dot{V}_{0}^{d r y}$ is the applied dry gas flow-rate, $\mathrm{p}_{0}$ and $\mathrm{T}_{0}$ the standard conditions and $\mathrm{p}_{\text {gas }}=\mathrm{p}_{\mathrm{OP}}-\mathrm{p}_{\mathrm{w}}$ the gas pressure using ideal gas law. However, the measured value is much higher than the estimation of the residence time just calculated. The theoretical residence time is around $0.8 \mathrm{~s}$, which means that in the real case the 

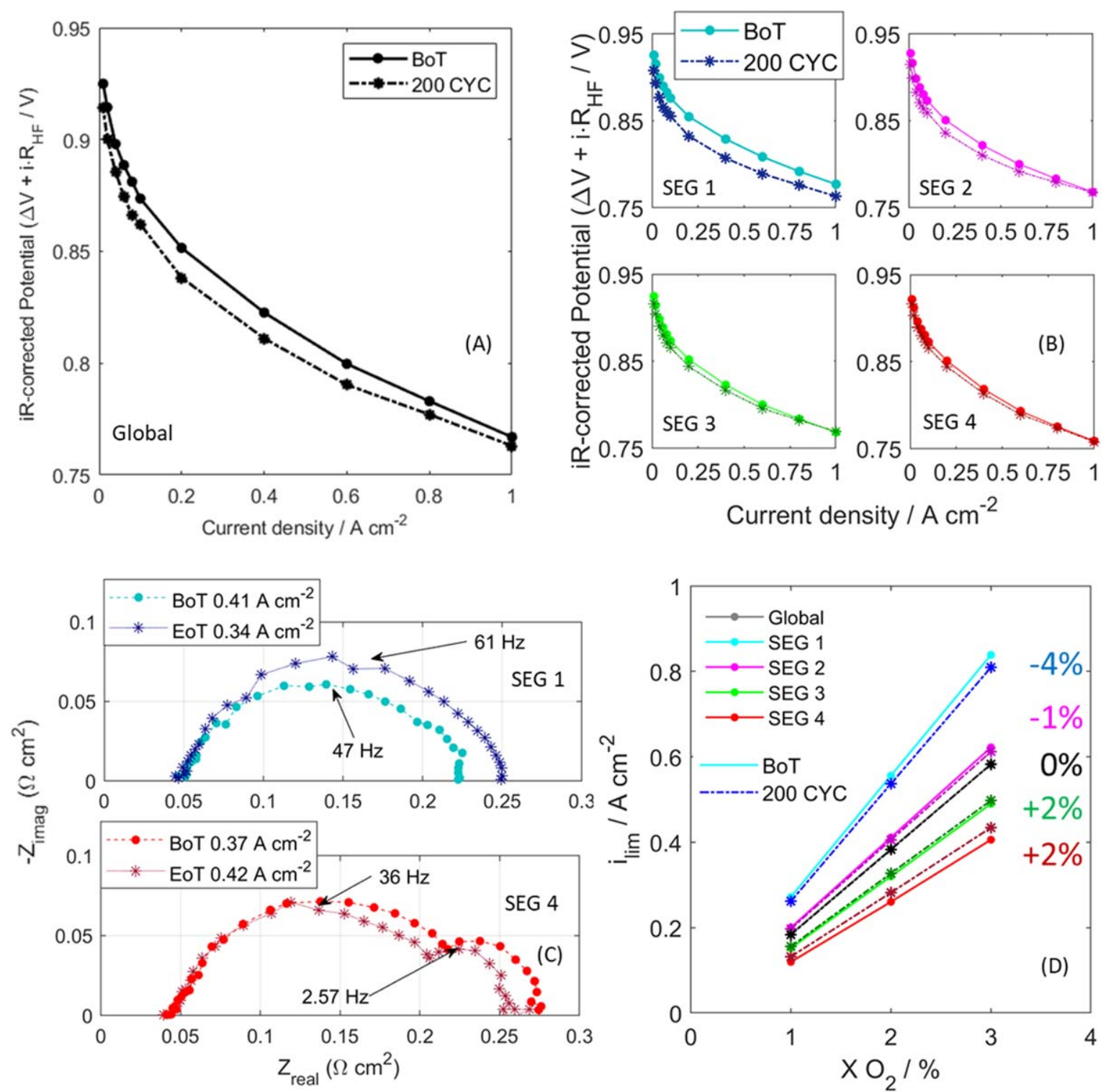

Figure 5. Local aging analysis after 200 cycles of mitigated start-up protocol in segmented-cell on JMFC MEA: (A) Overall $\mathrm{H}_{2} /$ Air polarization curve in condition: $\mathrm{T}=80^{\circ} \mathrm{C}, \mathrm{RH}=100 \%, \mathrm{p}_{\mathrm{an}} / \mathrm{p}_{\mathrm{ca}}=250 / 230 \mathrm{kPa}(\mathrm{abs})$, stoich. $\mathrm{An} / \mathrm{Ca}=2 / 4,(\mathrm{~B})$ detailed of local polarization curves, (C) Local EIS at segment 1 and segment 4 at $0.4 \mathrm{~A} \mathrm{~cm}^{-2}$ in $\mathrm{H}_{2} / \mathrm{O}_{2}$ polarization: $\mathrm{RH}=100 \% / 100 \%, \mathrm{~T}=80{ }^{\circ} \mathrm{C}, \mathrm{p}_{\mathrm{an}} / \mathrm{p}_{\mathrm{ca}}=250 / 230 \mathrm{kPa}(\mathrm{abs}),(\mathrm{D})$ Overall and local limiting currents measured at $\mathrm{T}=$ $80{ }^{\circ} \mathrm{C}, \mathrm{RH}=100 \%, \mathrm{P}=210 \mathrm{kPa}_{(\mathrm{abs})}$ and three oxygen concentration $\left(\mathrm{X}_{\mathrm{O} 2 \mathrm{dry}}=1 / 2 / 3 \%\right)$

duration is about $2 / 3$ times greater than the assumption of plug-flow model. The difference between theoretical and measured residence time can be attributed to several aspects: the progressive consumption of hydrogen as the front proceeds, the diffusion process in the electrodes and the increase of the capacitive current contributions associated to PtOx and double-layer, in particular in case of fast start-up transients. A more detailed discussion of these aspects is described in Refs. 45, 51.

After 1000/100 cycles of catalyst support AST and un-mitigated SU/SD respectively, the potential in the passive region increases from $1.4 \mathrm{~V}$ to $1.5 \mathrm{~V}$ and $1.57 \mathrm{~V}$ respectively during catalyst support AST and SU/SD, while it remains more stable at $1.3 \mathrm{~V}$ for the shutdown in both the tests.

A significant discrepancy was observed between SU/SD test and AST when analyzing the electrochemical impedance spectra (EIS) measured in the polarization curve under oxygen atmosphere, as shown in Fig. 4C. In the Nyquist plot, a large semicircle appears after 1000 cycles of AST, indicating an increase in the charge transfer resistance associated to the ORR reaction, ${ }^{52}$ together with the disappearance of the high frequency linear branch. In the case of
SU/SD, the behavior is more complex, with the appearance of a high frequency circular feature and a smaller increase of the charge transfer resistance circle. The presence of a high-frequency arc could be related to a new reaction kinetics. Specifically, also the anode suffers significant degradation during SU/SD, induced by potential cycling as described in Ref. 53. However, as shown by other authors, ${ }^{8}$ the SU/SD mechanism introduces heterogeneity in the catalyst layer properties affecting both rib/channel and through the channel, observable at high frequency and attributable to the variation either of the proton conductivity or of the double layer capacitance. This finding seems consistent with the asymmetry, in the local potential profiles, observed between the SU and the SD, as discussed above. All these results suggest that the un-mitigated SU/SD induced performance heterogeneity compared to the support AST, which will be carefully investigated in the case of mitigated SU/SD in the following.

The mitigated start-up/shut-down protocol.-To verify heterogeneous aging, mitigated SU/SD aging protocol applied to JMFC MEA for 200 consecutive cycles, aiming to identify specific differences in aging with respect to un-mitigated SU/SD operation 
discussed above. The mitigation of shut-down and the execution of the start-up is expected to introduce heterogeneity, located at the cathode inlet/anode outlet region in counter-flow configuration.

Polarization curve performed at BoT and EoT, are reported in Fig. 5A. A voltage loss of $-12 \mathrm{mV}$ at $0.4 \mathrm{~A} \mathrm{~cm}^{-2}$ after 200 cycles, is calculated, slightly more evident in the low current density range (below $0.5 \mathrm{~A} \mathrm{~cm}^{-2}$ ), possibly related to ECSA loss, which will be investigated in the following. Considering fading related to SU/SD in absence of any mitigation strategy discussed above $(-480 \mathrm{mV}$ loss at $0.4 \mathrm{~A} \mathrm{~cm}^{-2}$ after 100 cycles), this confirms the sensible positive effect of the introduced mitigation strategy in limiting overall detrimental effects.

Interesting insights are obtainable by means of localized investigation: Fig. 5B reports local polarization curves, focusing on lowcurrent density range, which permits to detail the local degradation in the kinetic region. From their comparison, a sensible heterogeneity appears in terms of performance loss, noticeably stronger at cathode inlet region, in consistency with the high potential occurring during start-up transient. The performance loss at $0.4 \mathrm{~A} \mathrm{~cm}^{-2}$ for the four segments (moving from cathode inlet, SEG 1, to outlet region, SEG 4) is respectively: $-22 \mathrm{mV},-13 \mathrm{mV}$ and smaller for the third and fourth segment $(-8 \mathrm{mV}$ and $-6 \mathrm{mV})$.

The spectra of local EISs, reported in Fig. 5C, confirm the substantial heterogeneity of the process. Comparing BoT and EoT local spectra, a general shrinking is noticeable, with again a noticeably different behavior localized at cathode inlet (SEG 1) with respect of the outlet regions of the MEA (SEG 4). In particular, for the first segment, current redistribution induced a reduction of the current density at which EIS is performed. For the fourth segment, two main effects occur: an increase of local current density (consistent with a reduction of the charge transfer resistance feature) due to current redistribution after start-up/shut-down cycling and the increase of oxygen concentration due to a reduced consumption in the first segment.

Cyclic voltammetry (reported in SI-1) confirms an uneven ECSA loss (reported in Fig. 9B) in the cathode catalyst layer. For an average ECSA loss of $25 \%$ with respect to BoT, local heterogeneity loss is evident beneath each segment. The largest loss is again localized at cathode inlet segment, confirming a harsher operation, progressively milder towards the outlet section of the electrode.

$\mathrm{H}_{2} / \mathrm{O}_{2}$ polarization curves (reported in SI-2) also demonstrate heterogeneous performance reduction, visible as a vertical translation in the $\mathrm{i}-\mathrm{V}$ chart. The largest voltage decrease regards SEG 1 and 2 (close to anode outlet), respectively $-11 \mathrm{mV}$ and $-11 \mathrm{mV}$ (at $0.4 \mathrm{~A} \mathrm{~cm}^{-2}$ ), while the performance of the SEG 3 and 4 is respectively unchanged and even slightly improved (due to current redistribution between the segments).

The kinetic performance loss due to the decrease of catalyst surface area (i.e. ECSA, in $\mathrm{m}_{\mathrm{Pt}}^{2} \mathrm{~g}_{\mathrm{Pt}}^{-1}$ ) is obtained from local cyclic voltammetry analysis.

According to Tafel kinetics:

$$
\eta_{O R R}=\frac{2.303 R T}{\alpha F} \log \left(\frac{i_{f c}}{i_{0} E C S A L_{P t}}\right)
$$

where $\alpha$ is the cathodic transfer coefficient (that is assumed equal to $\left.1^{54}\right), i_{f c}$ the current density in galvanostatic operation, $i_{O}$ the exchange current density and $L_{P t}$ the cathode platinum loading. Accordingly, the theoretical kinetic loss can be estimated by ECSA decline:

$$
\Delta \eta=\frac{2.303 R T}{\alpha F} \log \left(\frac{E C S A_{B o T}}{E C S A_{E o T}}\right)
$$

For the first segment the so-calculated theoretical voltage loss curve is $-14 \mathrm{mV}$, in good agreement with performance decay measured from $\mathrm{H}_{2} / \mathrm{O}_{2}$ polarization and discussed just above.
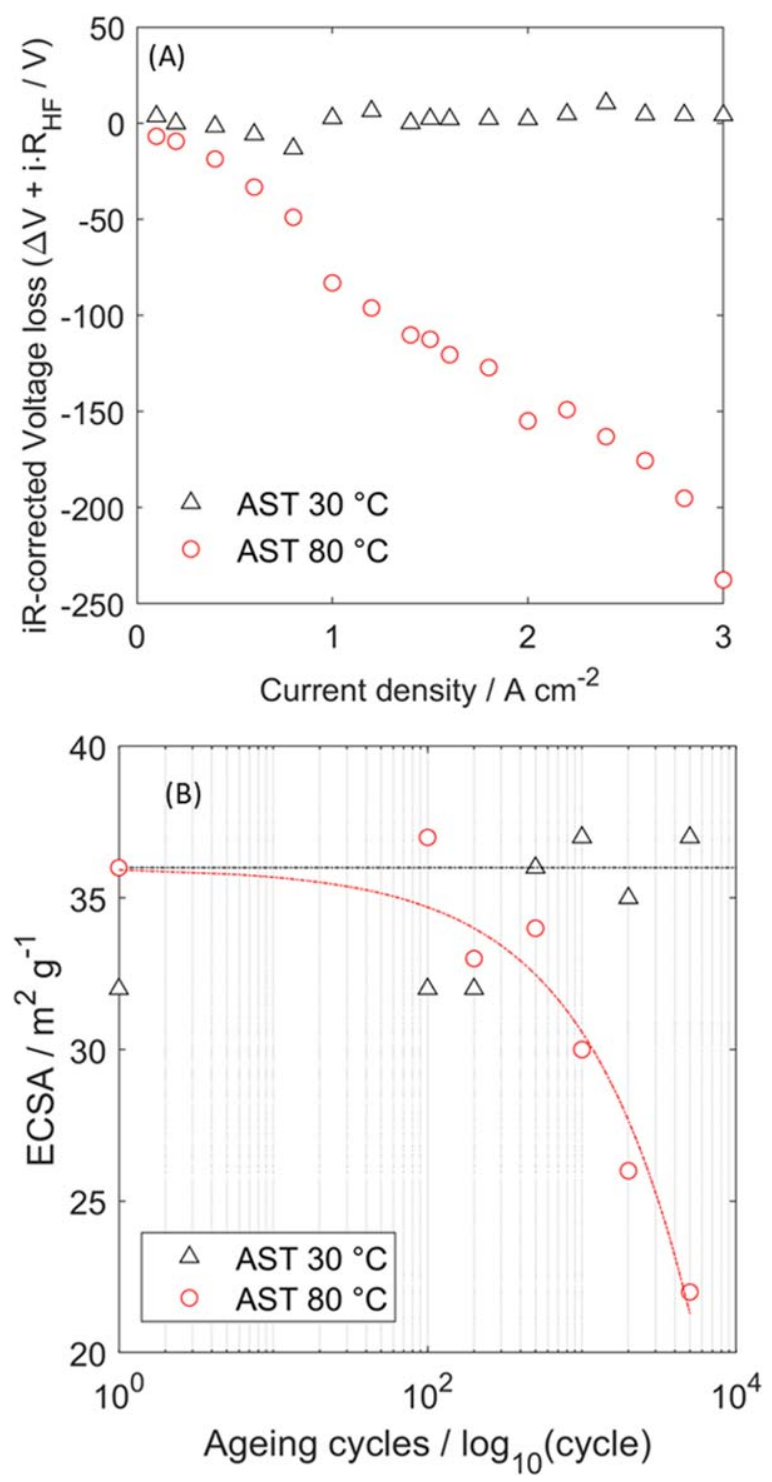

Figure 6. Effect of temperature on support ASTs in Zero-Gradient cell on JMFC MEA: (A) iR-corrected voltage loss measured in reference condition: $\mathrm{T}=80{ }^{\circ} \mathrm{C}, \mathrm{RH}=100 \%, \mathrm{p}_{\text {anode }} / \mathrm{p}_{\text {cathode }}=250 / 230 \mathrm{kPa}$, Stoich. An $/ \mathrm{Ca}=8 /$ 10 , minimum flux $=0.5 \mathrm{~A} \mathrm{~cm}^{-2}$ equivalent. (B) ECSA evolution during support ASTs conducted at $30{ }^{\circ} \mathrm{C}$ and $80{ }^{\circ} \mathrm{C}$. ECSA values were obtained during $\mathrm{CV}$ performed in $\mathrm{H}_{2} / \mathrm{N}_{2}$ (anode/cathode) at $30{ }^{\circ} \mathrm{C}, 100 \% \mathrm{RH}$ and ambient pressure.

Results of the limiting current test are shown in Fig. 5D and further confirm the heterogeneity of ageing among segments. Limiting current density values decrease between segments along channel direction, because of non-infinite stoichiometry that was set in the experiment. After 200 cycles, the oxygen transport resistance appears to be higher in the case of air inlet region, with notably largest changes at the first segment, while the third and fourth segment exhibit contrarily improved limiting current. In conclusion, a large difference is found between the degradation in the unmitigated and mitigated SU/SD. The difference was both quantitative (larger degradation is found for the un-mitigated case) and qualitative, because the voltage loss appears as an offset for any current density and localized in the air inlet region only. To get insight into these results, additional tests were performed in a zerogradient cell and a new AST protocol was defined to reproduce the degradation observed during mitigated start-up protocol. 


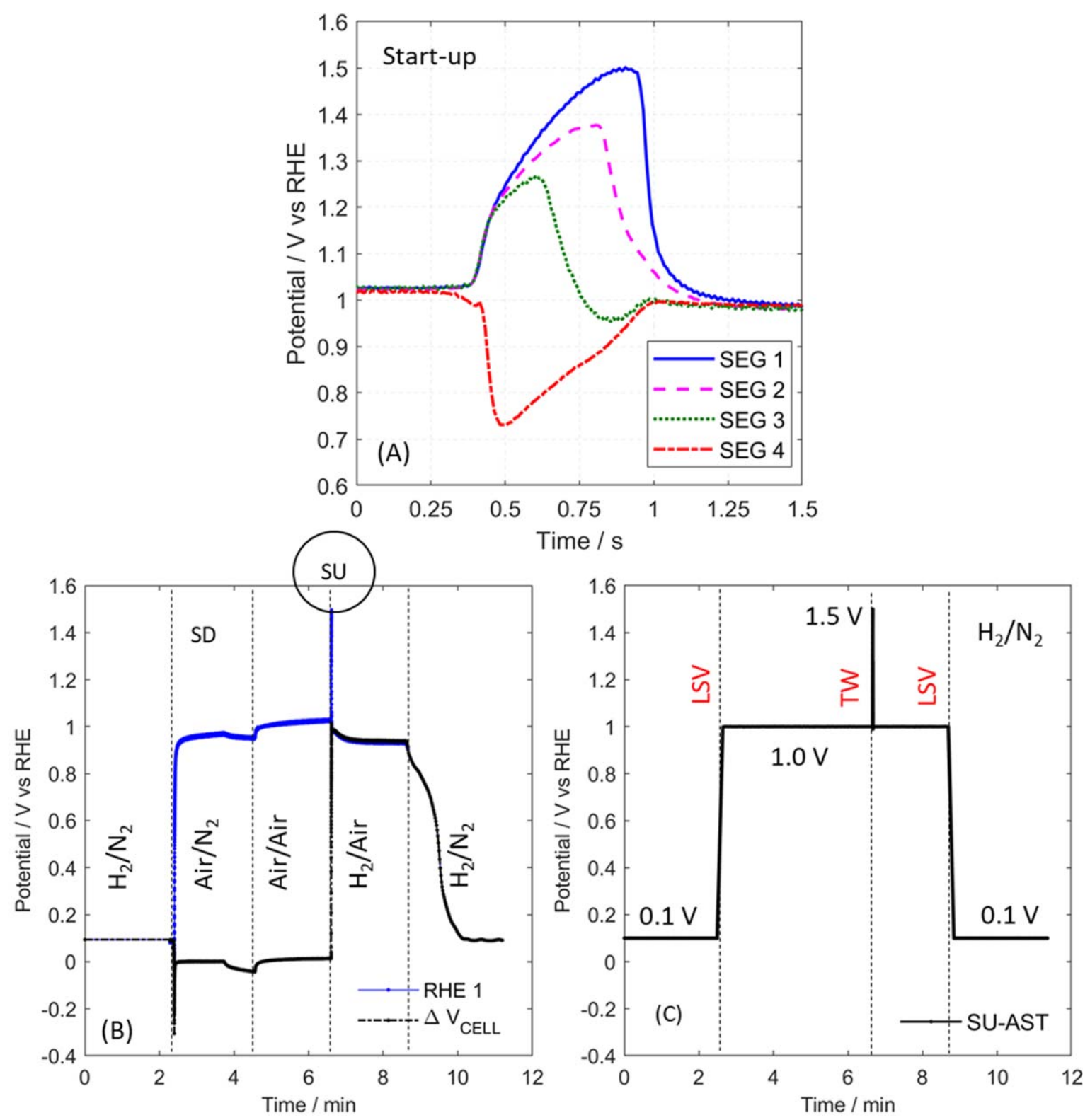

Figure 7. Potential profile during start-up operations on JMFC. (A) Local potential profile collected with RHE at four-segment regions during $\mathrm{H}_{2} /$ air front, (B) Comparison between local potential profile at cathode inlet position and cell voltage during one cycle of mitigated start-up in segmented-cell, (C) Potential profile adapted for start-up AST performed in zero-gradient cell.

SU-AST protocol development and validation.-Existing AST protocols that selectively induce electrocatalyst or support degradation were analyzed, and the results compared with the degradation consequent to the mitigated start-up protocol. No satisfactory agreement was found, differently from the previous case where un-mitigated start-up was analyzed. A possible explanation is a difference in the dominant degradation mechanism in the process, as later discussed in this work when post-mortem results are presented.

Temperature effect on catalyst support AST.-Temperature impact on degradation was analyzed by applying consecutive cycles of potential between 1.0 and $1.5 \mathrm{~V}$ such as in DoE support AST both at $80^{\circ} \mathrm{C}$ and $30{ }^{\circ} \mathrm{C}$. All material testing results have been realized adopting the zerogradient cell. Performance evolution was compared by polarization curves and ECSA measurements and results are reported in Fig. 6.

At $80{ }^{\circ} \mathrm{C}$, the ECSA reduces by $17 \%$ between 1 and 1000 cycles and decreases by $41 \%$ in the last 4000 cycles. To evaluate the performance loss induced by voltage cycling, iR-free differential curves were compared at BoT and EoT. The voltage loss was respectively:
$-83 \mathrm{mV}$ at $1 \mathrm{~A} \mathrm{~cm}^{-2}$. After 5000 cycles, the theoretical voltage loss is $-15 \mathrm{mV}$ according to Tafel kinetics as expressed in Eq. $9\left(\mathrm{ECSA}_{\mathrm{BoT}}=\right.$ $\left.36 \mathrm{~m}^{2} / \mathrm{g}_{\mathrm{Pt}}, \mathrm{ECSA}_{\mathrm{EoT}}=22 \mathrm{~m}^{2} / \mathrm{g}_{\mathrm{Pt}}, \alpha=1\right)$. The experimental results are higher compared to the theoretical calculations, suggesting that also worsening of proton and oxygen transport are involved.

In Fig. 6, low temperature $\left(30^{\circ} \mathrm{C}\right)$ support AST presents different results in terms of degradation effects than high temperature AST. The active area increases uniformly during AST. In the first 500 cycles ECSA can be considered constant and reach the maximum value after 1000 cycles, after 5000 cycles the ECSA value is still $14 \%$ higher than at the beginning of test. Hence, in terms of ECSA, a degradation effect is not identified, confirming the mitigation role of the temperature, which has a strong impact on carbon corrosion kinetics. Despite the standard activation procedure has always been applied to all the samples adopted in the work, ECSA has been found to increase in the first operation period for certain tests. Likewise, performance loss is negligible at EoT, high voltage cycling is known to be a method for reversible recovery of ECSA after degradation; sulphur based pollutants can be effectively removed. ${ }^{55-57}$ 

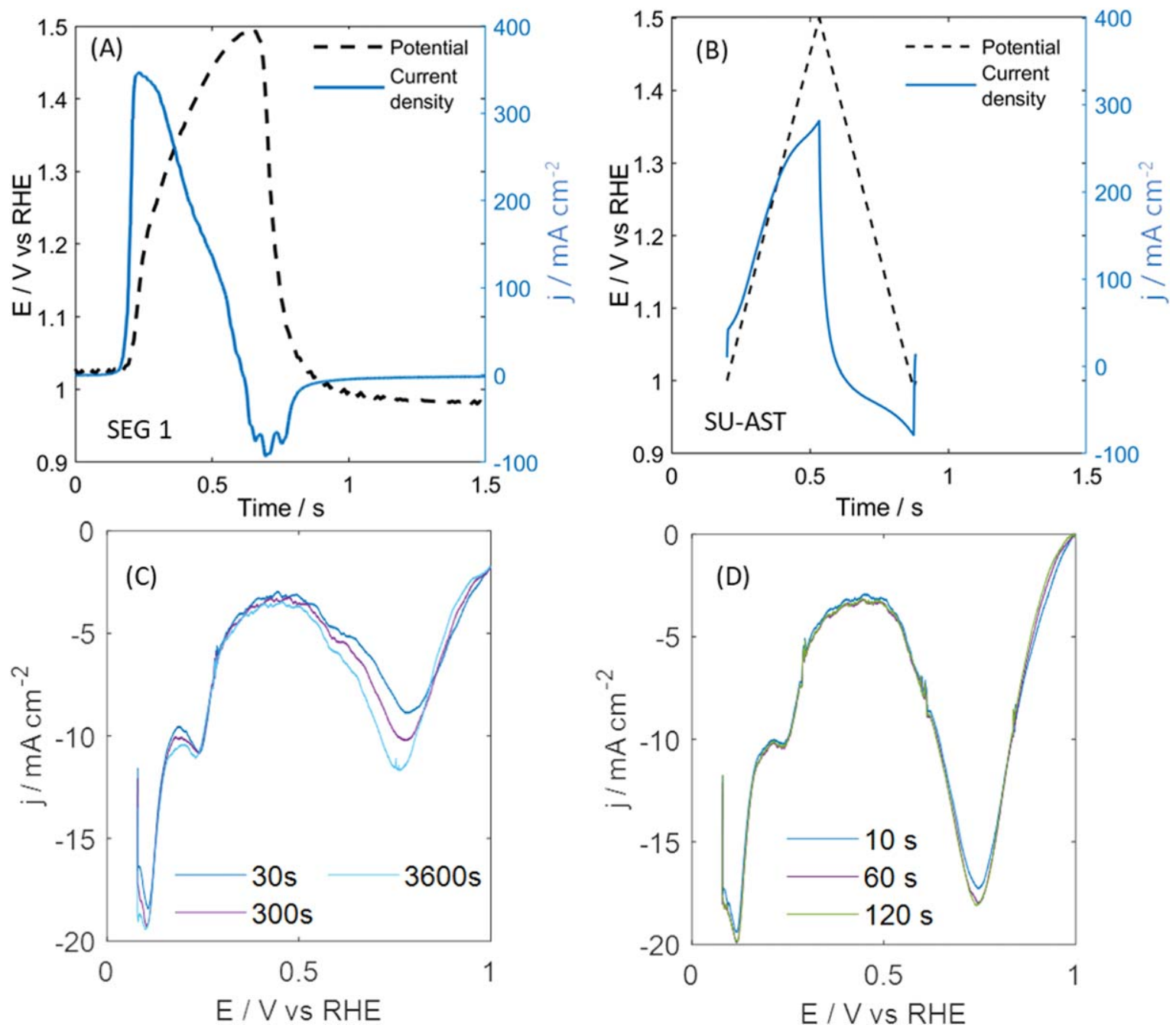

Figure 8. Comparison of potential and current density during start-up operations on JMFC: (A) segment 1 in segmented-cell, (B) start-up AST, (C) PtOx reduction current after step 2 in AST, (D) PtOx reduction current after step 4 in AST.

To clarify the observed results, a potential analysis has been performed focusing on the local transient during $\mathrm{H}_{2}$ /air front in mitigated start-up protocol. Cathode potential measured in four locations along the channel (see Fig. 1A) is depicted in Fig. 7A highlighting the onset of a sudden, strongly heterogeneous response to the procedure.

As visible, a potential as high as $1.5 \mathrm{~V}$ vs RHE is reached at cathode electrode in the inlet segment (SEG 1 in Fig. 7A), while a much lower potential (approaching $0.7 \mathrm{~V}$ vs RHE) is progressively reached moving towards the outlet segment (SEG 4 in Fig. 7).

The main difference that is noticeable compared to the case of start-up/shut-down performed in segmented-cell is the presence of a low potential period for each cycle (around $0.1 \mathrm{~V}$ vs RHE). As a consequence, in the worst case of the cathode inlet (anode outlet), as shown in Fig. 7A, the potential sweeps between $0.1 \mathrm{~V}$ and $1.5 \mathrm{~V}$. Considering the negligible performance loss observed in catalyst support AST at $30{ }^{\circ} \mathrm{C}$, the result suggests that the cause of the observed degradation is linked with the wide potential cycling adopted that could accelerate the Pt dissolution. Instead, the contribution of carbon corrosion at low temperature with respect to that at high temperature appears to be lower, as discussed by other authors. ${ }^{50}$

In conclusion, catalyst support AST at $30^{\circ} \mathrm{C}$ was not effective to reproduce performance loss observed at segment 1 , during mitigated protocol, and hence a new protocol development is required.

Start-up protocol development.-A new AST protocol was developed (hereinafter defined Start-up Accelerated Stress Test, SU-AST), aiming to reproduce the local degradation identified at the air inlet in the mitigated start-up test performed in the segmented-cell hardware.

The definition of the SU-AST started from the analysis of the local cathode potential measured by RHE, focusing on the first segment, identified as the passive region during start-up, because the local degradation rate is higher.

The steps that compose the mitigated start-up protocol are reported in Table V. During the cycle, the potential profile at cathode inlet (i.e. SEG 1) and the cell voltage were collected and results are reported in Fig. 7B. After the refresh period under $\mathrm{H}_{2} / \mathrm{N}_{2}$, air was fed in the anode compartment. Potential increased at about $1 \mathrm{~V}$ vs RHE and remained almost constant until the end of the cycle with a fast voltage cycling at $1.5 \mathrm{~V}$ during $\mathrm{H}_{2}$ /air front.

This potential profile, measured by means of RHE measurement, was the target of the new AST cycle. The new SU-AST proposed is consistently performed at low temperature (i.e. $\mathrm{T}=30{ }^{\circ} \mathrm{C}$ as the mitigated SU/SD cycling) and with the fuel cell fed by $0.06 \mathrm{Nl}$ $\min ^{-1}$ of $\mathrm{N}_{2}$ at the cathode and by $0.060 \mathrm{Nl} \mathrm{min}-1$ of $\mathrm{H}_{2}$ at the anode, as summarized in Table V.

To simplify the shape of the voltage profile in real start-up and increase reproducibility, a triangular sweep cycle is proposed. Cathode potential is symmetrically scanned at $1.5 \mathrm{~V} \mathrm{~s}^{-1}$ rate between $1.0 \mathrm{~V}$ and $1.5 \mathrm{~V}$ vs RHE.

Effect of potential cycling during start-up.--Results obtained with SU-AST were compared to the mitigated start-up potential and 

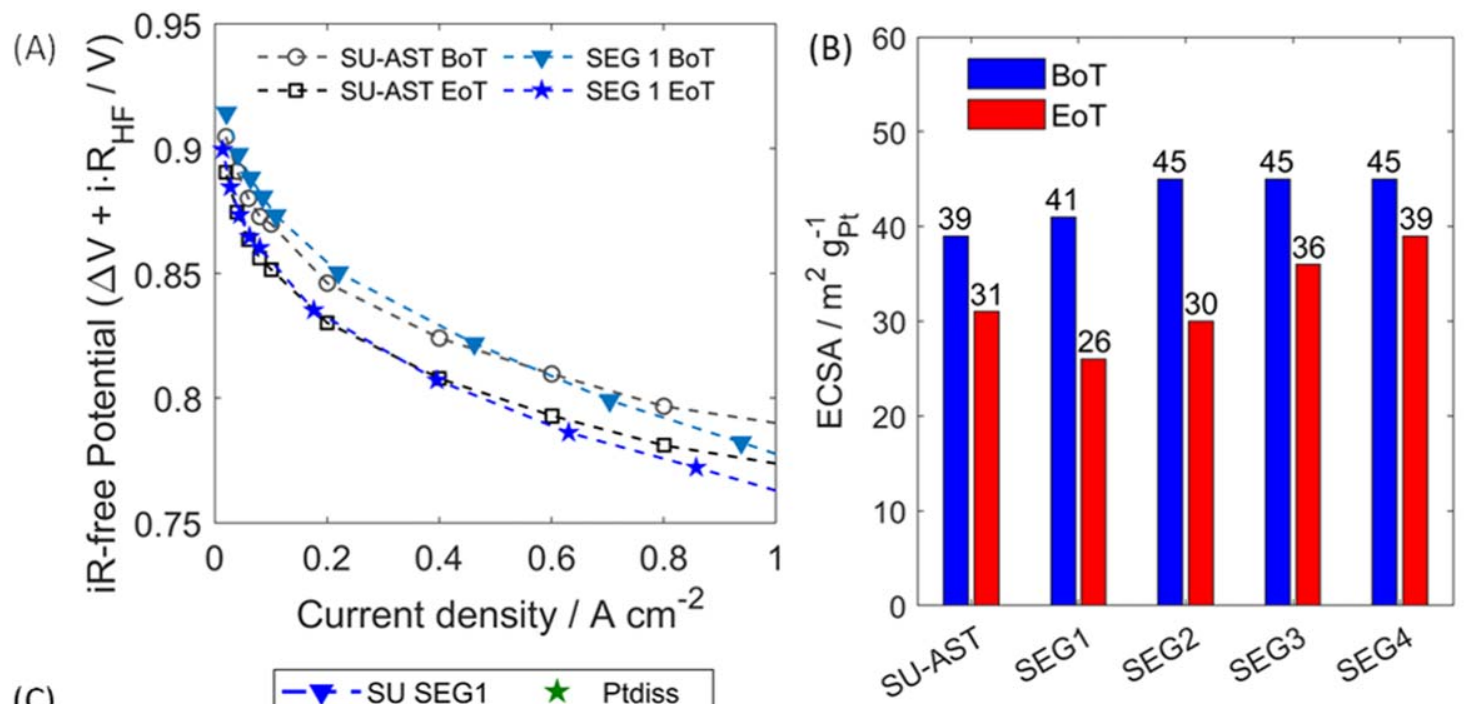

(C)

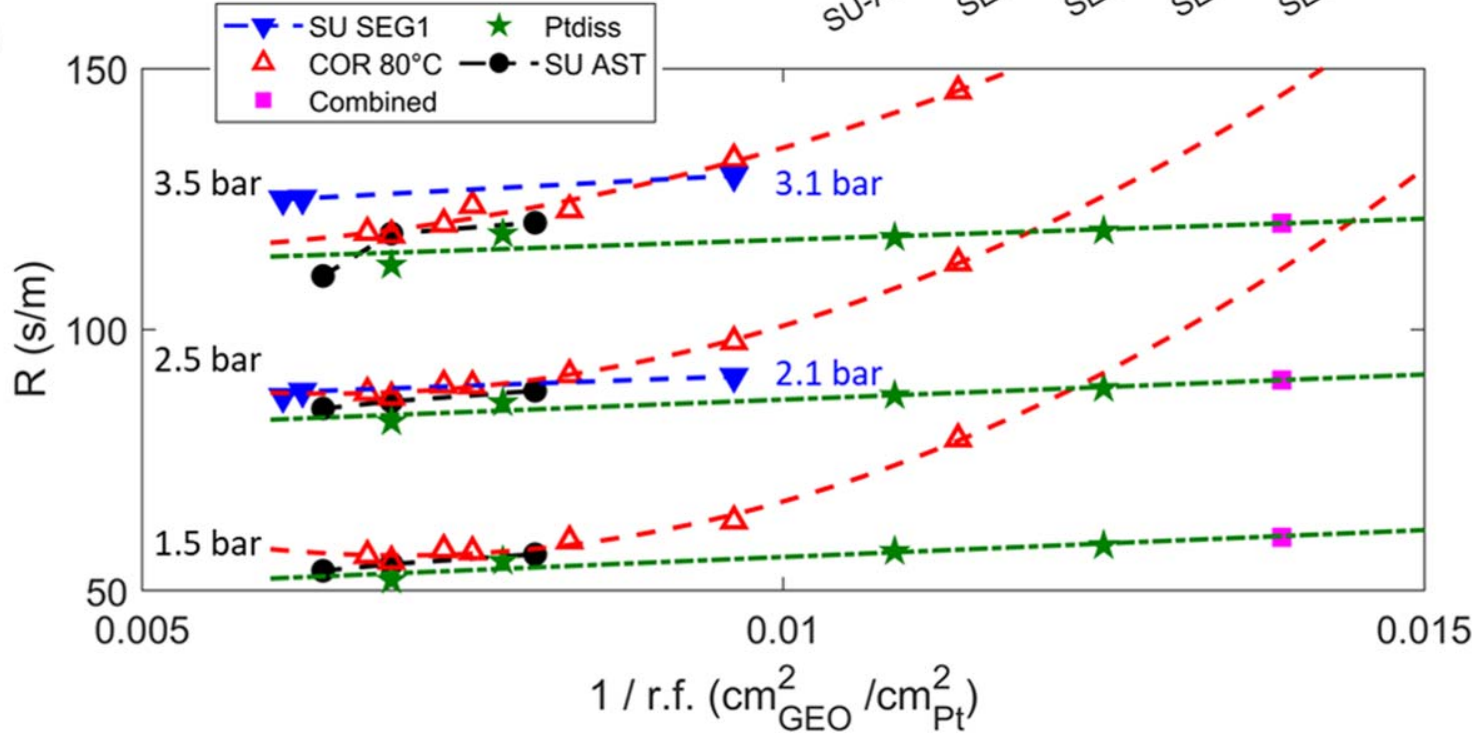

Figure 9. Comparison between start-up AST and cathode inlet segment of mitigated start-up/shut-down after 200 cycles of operation on JMFC. (A) iR-free $\mathrm{H}_{2} /$ Air polarization curves measured at $\mathrm{T}=80{ }^{\circ} \mathrm{C}, \mathrm{RH}=100 \%, \mathrm{p}_{\text {anode }} / \mathrm{p}_{\text {cathode }}=250 / 230 \mathrm{kPa}$, the full symbols represent segment 1 of $\mathrm{MEA}$ in $25 \mathrm{~cm}{ }^{2}$ segmented-cell while the open symbols is the $10 \mathrm{~cm}^{2}$ MEA in zero-gradient cell; (B) ECSA comparison for AST and mitigated SU/SD at each MEA segment; (C) Oxygen transport resistance plotted against the inverse roughness factor for 3 different pressures in zero-gradient cell $(\mathrm{P}=150 / 250 / 350 \mathrm{kPa}(\mathrm{abs})$, and 2 pressures for segmented-cell $\left(\mathrm{P}_{\mathrm{SU}-\mathrm{SEG} 1}=210 / 310 \mathrm{kPa}(\mathrm{abs})\right.$ ). For each point $\mathrm{R}_{\mathrm{T}}$ was interpolated from 3 different oxygen concentrations $\left(\mathrm{X}_{\mathrm{O} 2 \mathrm{dry}}=1 / 2 / 3 \%\right)$. The reported tests for zero-gradient cell are: electrocatalyst AST (Ptdiss), catalyst support AST at $80{ }^{\circ} \mathrm{C}\left(\mathrm{COR} 80{ }^{\circ} \mathrm{C}\right)$, start-up AST at $30{ }^{\circ} \mathrm{C}(\mathrm{SU}$ AST), sequence of electrocatalyst/start-up AST (Combined); while local resistance at segment 1 is named SU SEG1.

current profile, as reported in Fig. 8. A consistent profile was found for both local currents and potentials, indicating the reliability of the AST in reproducing the process occurring on cathode electrode associated to mitigated SU/SD operation. As noted, the potential and current profiles are similar in both cases, although minor differences are found and attributed to capacitive/pseudo-capacitive effect. To better understand these effects, and in particular the role associated with platinum oxides and link them with platinum dissolution mechanism, a sensitivity analysis was carried out on the formation and reduction of platinum oxides on the material under study. The impact of the different zones of voltage profile during a cycle of start-up AST (see Table V) has been studied by linear sweep voltammetry (LSV) and the results are reported in Figs. 8C and 8D.

To simulate the AST's region 2), a holding time variable between $30 \mathrm{~s}$ and $3600 \mathrm{~s}$ at $1 \mathrm{~V}$ vs RHE was applied, then LSV down to $0.08 \mathrm{~V}$ vs RHE was performed to investigate the reduction peaks. Looking at the results is evident that, in terms of PtOx formation, the first holding time at $1 \mathrm{~V}$ cause a progressive increase of platinum reduction charge. Analogously, the AST cycle was performed and AST region 4) was analyzed after different holding time by means of
LSV down to $0.08 \mathrm{~V}$ vs RHE; results are reported in Fig. 8D. It was evident that most of $\mathrm{Pt}$ oxides were formed at potential up to $1 \mathrm{~V}$, however, keeping the MEA at $1 \mathrm{~V}$ for $30 \mathrm{~s}$ or $120 \mathrm{~s}$ does not significantly change the reduction peak. Platinum oxides reach a quasi-steady state during voltage cycling at $1.5 \mathrm{~V}$ vs RHE (i.e. the start-up) and were reduced only during the last voltage sweep from $1 \mathrm{~V}$ to $0.1 \mathrm{~V}$ vs RHE.

The continuous change of $\mathrm{Pt}$ surface state, due to oxidation and reduction mechanism, seems to be linked to the degradation process observed. Thus, it partially elucidates the heterogeneous performance loss which was observed under mitigated SU/SD from cathode inlet (i.e. $0.1-1.5 \mathrm{~V}$ ) to cathode outlet (i.e. $0.1-1.0 \mathrm{~V}$ ) and sheds light on the different performance loss observed under the SUAST with respect to the catalyst support AST performed at $30^{\circ} \mathrm{C}$, as discussed below.

Performance loss induced by new AST protocol.-To demonstrate the consistency of the SU-AST in terms of aging effects, 200 cycles were performed on the zero-gradient cell hardware and were compared to 200 mitigated SU/SD cycles operated in the segmented- 

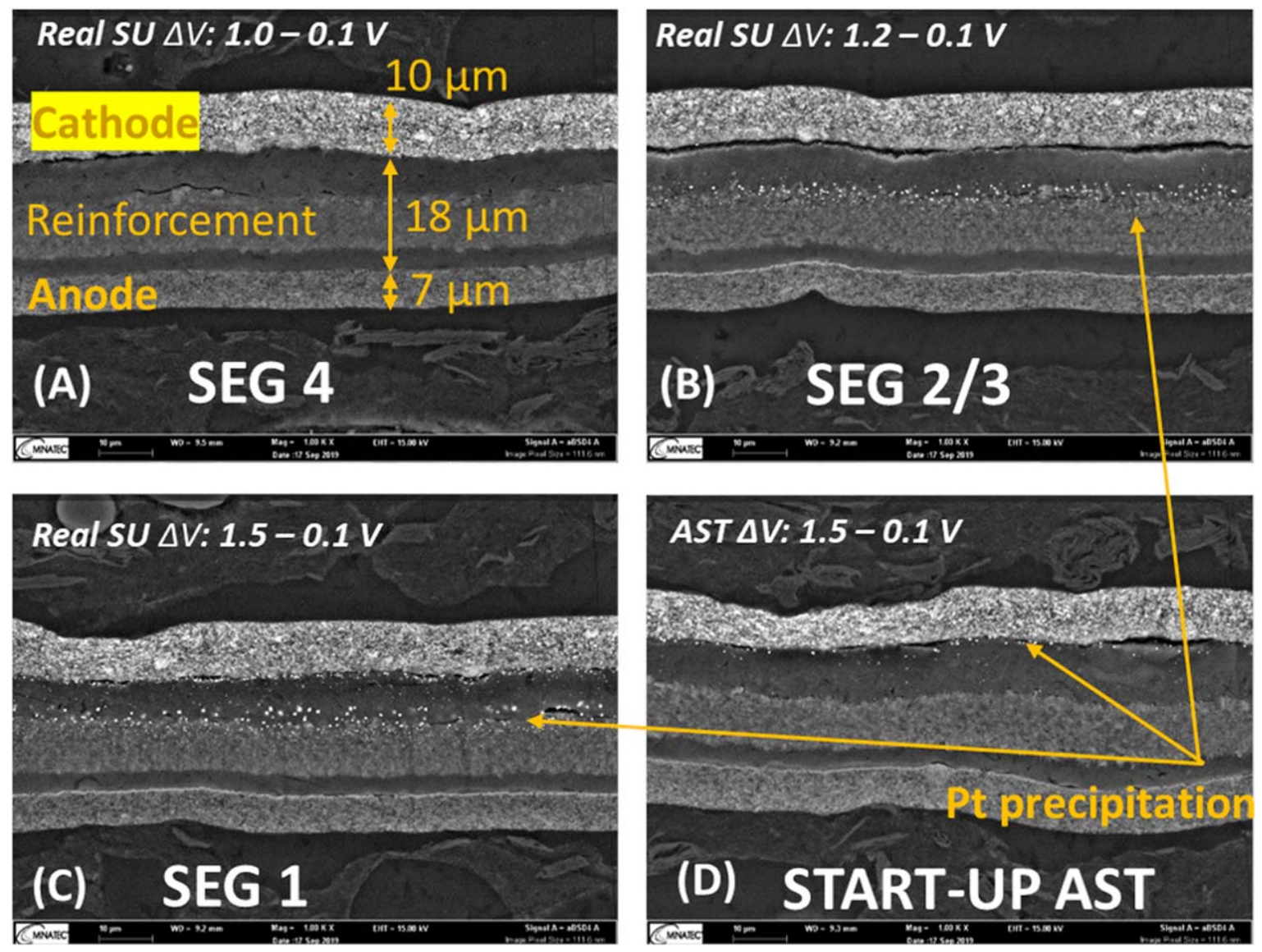

Figure 10. SEM images of aged materials (JMFC MEA) during mitigated start-up in segmented-cell ( $\mathrm{H}_{2} /$ Air front) after 200 cycles: (A) Cathode outlet (anode inlet), (B) cathode middle, (C) cathode inlet (anode outlet). (D) SEM image on aged materials during Start-up AST.

cell hardware. In order to enable a direct comparison between tests on the two different hardware, iR-free polarization curves are plotted in Fig. 9A. For the scope, this correction makes acceptable the comparison between the two hardware, at least up to $1 \mathrm{~A} \mathrm{~cm}^{-2}$. At higher current, oxygen and liquid water transport effects related to the flow field geometry become relevant.

The results demonstrate a noticeably good reliability for the SUAST in reproducing the effects of actual SU/SD operation localized at cathode inlet. The performance loss is respectively: $-21 \mathrm{mV}$ and $-22 \mathrm{mV}$ (at $0.4 \mathrm{~A} \mathrm{~cm}^{-2}$ ) for the real SU in segmented-cell (at cathode inlet) and SU-AST in zero-gradient cell. In iR-free $\mathrm{H}_{2} / \mathrm{O}_{2}$ polarization curves, the performance evolution is visible as a vertical translation, though a slight difference on voltage loss was observed: $-11 /-6 \mathrm{mV}$ (at $0.4 \mathrm{~A} \mathrm{~cm}^{-2}$ ) for real SU at cathode inlet and SU-AST.

In terms of ECSA loss, the degradation obtained at 200 cycles of the SU-AST is comparable with the one obtained in the first segment, as presented in Fig. 9B, supporting again a good representativeness of the proposed AST.

To conclude the comparison, the evolution of oxygen mass transport resistance over the inverse of roughness factor is reported, to highlight ECSA evolution effect on performance and elucidate the degradation mechanism. In Fig. 9C, the results of real start-up and SU-AST are reported and compared with DoE electrocatalyst protocol and support protocol, both performed at $80^{\circ} \mathrm{C}$, and finally with a combined protocol that consist of a sequence of electrocatalyst AST at $80{ }^{\circ} \mathrm{C}$ and start-up AST. First, it is important to point out that the shape of the flow-fields in zero-gradient and segmented hardware are different: the land of segmented-cell flow-field is almost three times the land of zero-gradient cell flow-field. For this reason, limiting currents are lower in the segmented-cell leading to higher oxygen transport resistance $\left(R_{T}\right)$, e.g. the $R_{T}$ value at 2.5 bar $_{\mathrm{abs}}$ for the zero-gradient and the segmented cell were respectively:
$80 \mathrm{~s} \mathrm{~m}^{-1}$ and $100 \mathrm{~s} \mathrm{~m}^{-1}$ (obtained by linear interpolation between 2.1-3.1 bar $_{\mathrm{abs}}$ ). Thus, the $R_{T}$ values, described in Fig. 9C for the segmented-cell test, are reported at the pressure of 2.1 and 3.1 bar to be compared with the results in zero-gradient hardware.

The evolution of the $R_{T}$, in the case of the electrocatalyst AST was analyzed. At each AST stop, the limiting current $i_{\text {lim }}$ have been measured at three different oxygen concentration (i.e. 1-2\%-3\% dry gas) and at three pressure values. Following the procedure described in the experimental, the computed value of $R_{T}$ can be visualized as a function of the inverse of the roughness factor, r.f. ${ }^{-1}$. A linear correlation is found and slope of the straight line through the r.f. ${ }^{-1}$ values for each test pressure was found as: $10 \mathrm{~s} \mathrm{~cm}^{-1}$ at $150 \mathrm{kPa}$, $10 \mathrm{~s} \mathrm{~cm}^{-1}$ at $250 \mathrm{kPa}$ and $7.5 \mathrm{~s} \mathrm{~cm}^{-1}$ at $350 \mathrm{kPa}$ (for tests performed at $80^{\circ} \mathrm{C}$ and $\mathrm{RH}=100 \%$ ). These values are very similar to the one that Greszler observed in limit current measurements carried out on electrodes over a wide range of catalytic loads (from 0.03 to 0.4 $\left.\mathrm{mg}_{\mathrm{Pt}} \mathrm{cm}^{-2}\right) .{ }^{41}$ According to Baker et al. the oxygen-transport resistance can be separated into two different contributions: one dependent on pressure $\left(R_{P D}\right)$, representing bulk transport in the channel, diffusion media, and electrode, and a pressure-independent resistance $\left(R_{P I}\right)$. The two contributions were calculated from the value of $R_{T}$ as a function of pressure, in the limit $\mathrm{p} \rightarrow 0$, representing non-Fickian transport in the electrode, including local oxygen electrode resistance due to permeation across ionomer, as described in Refs. 58, 59 Additionally, for the electrocatalyst AST, the computed value of $R_{P I}$ fit a straight-line as a function of r.f. ${ }^{-1}$, and the regression slope, $R_{O 2, P t}$ is $=12 \mathrm{~s} \mathrm{~cm}^{-1}$, according to Greszler et al. ${ }^{59}$

Following consecutive cycles between $0.6-0.95 \mathrm{~V}$ vs RHE a reduction of ECSA was observed. The Pt dissolution process is the dominant mechanism attributable to ECSA loss in the potential range of the electrocatalyst $\mathrm{AST}^{60}{ }^{6}$ that led to a decrease of the number of catalyst sites available for the ORR reaction. 

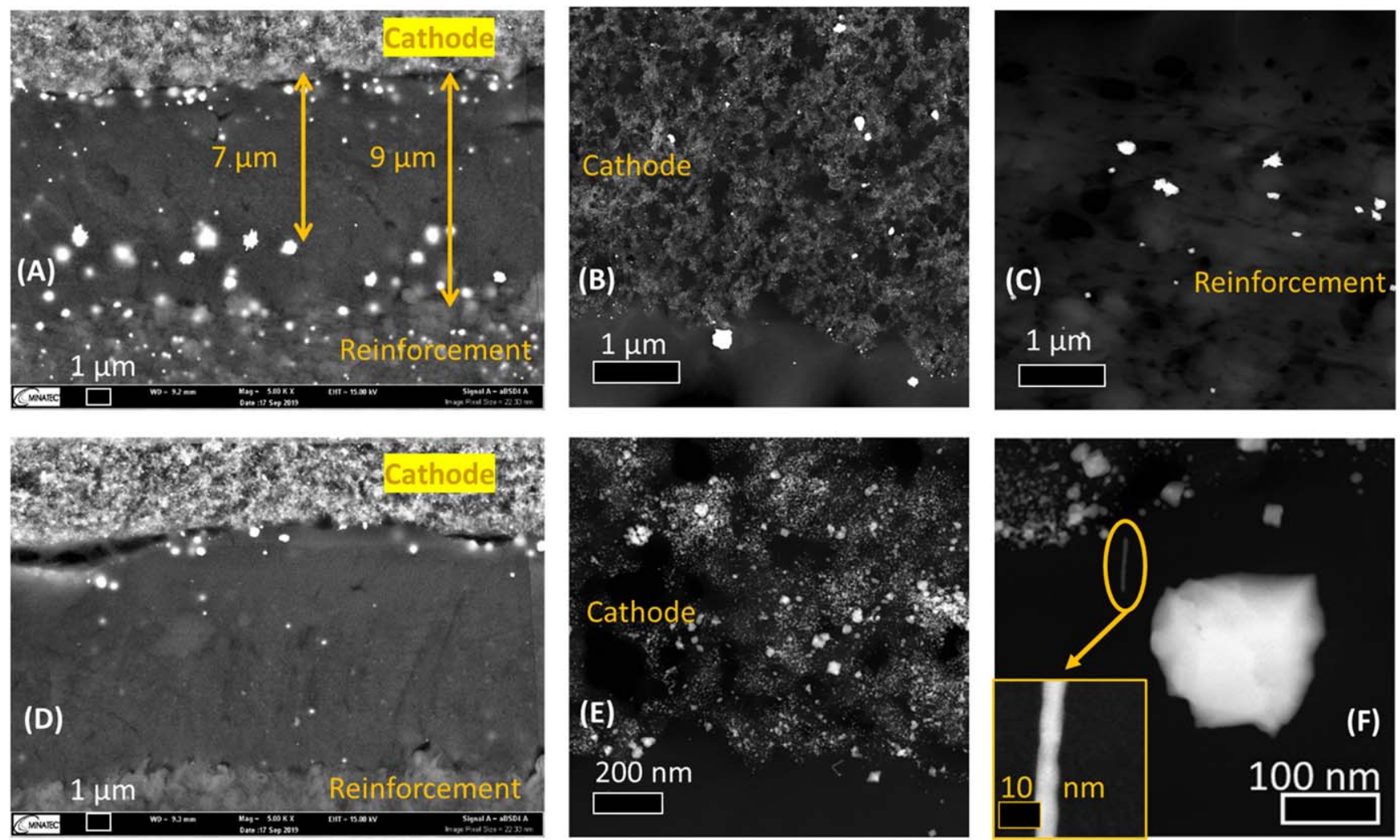

Figure 11. SEM/TEM images of cathode catalyst after the durability test at cathode inlet in mitigated start-up/shut-down on JMFC: (A) The Pt band can be identified near membrane reinforcement, (B) CCL/membrane interface, (C) reinforcement. SEM/TEM images of cathode catalyst after the durability test in startup AST: (D) Pt precipitates located near MEM/CCL interface, (E) TEM image of cathode electrode near membrane, (F) large Pt precipitate in cathode ionomer.

As discussed by Weber et al., ${ }^{61}$ the local resistance is attributable to local effects at catalyst sites, specifically oxygen permeation across the ionomer film covering the nanoparticle, not the specific activity of the single site. So, the increase of oxygen resistance is proportional to the increase of flux per Pt site. Based on the observed result, the link is confirmed both for electrocatalyst AST and SU-AST.

As reported in scientific literature, ${ }^{62,63}$ due to Pt dissolution and diffusion into the membrane, there is a more pronounced Pt loss at the membrane/CCL interface. However, no effects of this phenomenon have been observed in the tested materials even at EoT (i.e. after $30 \mathrm{k}$ cycles when relative ECSA $=57 \%$ ).

As shown in Fig. 9C, the linear relationship observed for a $\mathrm{Pt}$ dissolution mechanism, as in electrocatalyst $\mathrm{AST},{ }^{59}$ is no longer valid for the support AST. Here, the evolution of $R_{T}$ during AST is well-fitted with a quadratic function, in accordance with the degradation of electrode microstructure as foreseen by studies on carbon corrosion mechanism. Moreover, a similar trend was also observed by Kneer et al. ${ }^{59}$ on a start-up/shut-down test at high temperature $90{ }^{\circ} \mathrm{C}$, who have highlighted a more pronounced increase of pressure-independent term than pressure-dependent one, as expected if the degradation mainly occurs in the electrode.

However, in the case of the mitigated start-up and in the case of the start-up AST a linear trend was observed between the beginning and the end of life after 200 cycles, as observed under electrocatalyst AST. The most interesting result is the correlation between oxygen transport resistance and the ECSA value. From the condition reached under electrocatalyst AST, the start-up AST leads to decrease of the catalyst active area by an additional $6 / 7 \%$ with respect to the BoT value. Combining this information with the oxygen transport resistance, the point obtained at 200 start-up cycles lies perfectly on the line obtained for the only Electrocatalyst AST, as visible in Fig. 9C. The linear and equivalent trend confirms that the two degradation mechanisms lead to the same oxygen transport resistance change.
Post-mortem analysis.-To clarify the underlying degradation mechanism during start-up cycling, SEM and TEM analyses were performed on aged MEAs. MEA cross-sections have been first analyzed by SEM for both the MEAs aged under mitigated SU/SD degradation test in segmented-cell, and under start-up AST in zerogradient cell. For the segmented-cell aged MEA, the three crosssectional samples taken at different position of the cathode electrode surface area, air inlet (SEG 4), middle (SEG 2/3) and air outlet (SEG 1) positions, were observed while one sample was prepared from the zerogradient cell. Results of mitigated SU/SD operation in segmented-cell (i.e. $\mathrm{H}_{2}$ /Air operations) and start-up $\operatorname{AST}\left(\mathrm{H}_{2} / \mathrm{N}_{2}\right.$ operations) are depicted in Fig. 10.

SEM images after 200 cycles of start-up protocols (Figs. 10A-10C), do not reveal any severe thinning of cathode electrode, thus severe carbon corrosion can be excluded in both the operations, as observed commonly in start-up/shut-down at high temperature.

However, platinum precipitates were observed in the membrane; the intensity and the position of the precipitate bands are different between the samples. While a higher intensity of the $\mathrm{Pt}$ band characterizes the air inlet (Fig. 10C), it is less pronounced in the middle (Fig. 10B) and almost absent in the outlet section (Fig. 10A). The observations are in good accordance with the maximum potential reached during operation. Despite the entire cathode electrode sweep to high potentials (till $1 \mathrm{~V}$ vs RHE), the large Pt precipitates were formed at the passive zone of the start-up operation.

The SEM analyses of the MEA operated under SU-AST in zerogradient cell (Fig. 10D) also show Pt precipitation within the membrane, however the precipitation appears less intense and close to the CCL.

Figure 11 shows higher magnification SEM images and TEM images of $\mathrm{CCL} /$ membrane interface, aged in segmented-cell at segment 1 (Figs. 11A-11C) and zero-gradient cell (Figs. 11D-11F). These images highlight that for the MEA aged in segmented-cell at segment 1 the main precipitate band is located in the membrane near 

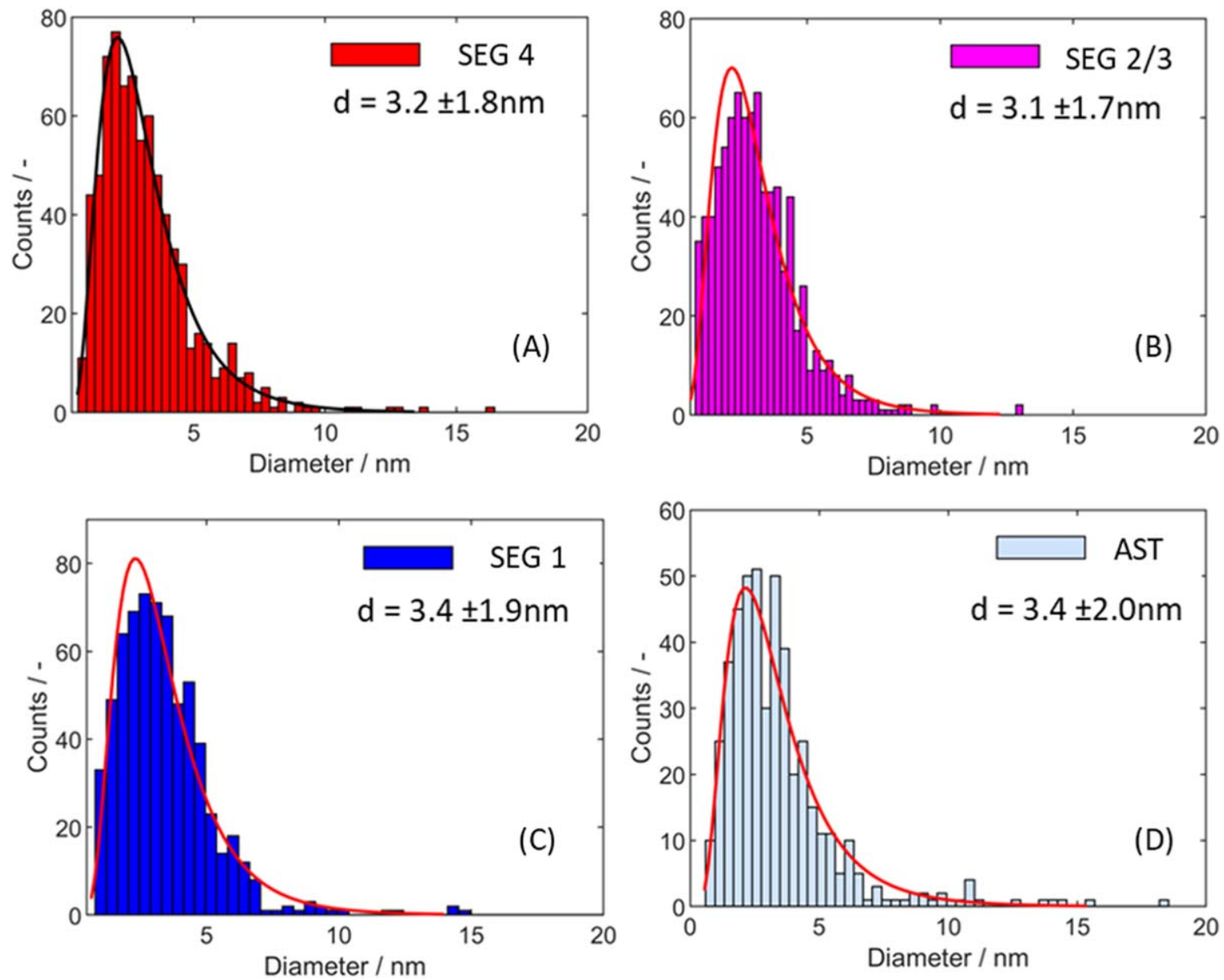

Figure 12. Pt particle size distribution on aged JMFC MEA, (A) cathode outlet (anode inlet) real start-up (SEG 4), (B) cathode middle (SEG 2/3), (C) cathode inlet (anode outlet, SEG 1), (D) start-up AST.

Table V. Parameters during Start-up: AST steps and mimicked operation during real Start-up cycle in segmented-cell.

Mitigated start-up in segmented-cell

Cycle

Cycle duration

Temperature

RH

Pressure

Reactants

\author{
1) refresh $\mathrm{H}_{2} / \mathrm{N}_{2}$ at $\mathrm{OCV}$ for $5 \mathrm{~min}$ (Stop with valve closed) \\ Air infiltration in stack due to leakages \\ 2) Air $/ \mathrm{N}_{2}$ and Air/Air, long stop at ambient temperature \\ Hydrogen/Air front at anode compartment \\ 3) Start-up \\ $\mathrm{H}_{2} /$ Air operation \\ $660 \mathrm{~s}$ \\ $30{ }^{\circ} \mathrm{C}$ \\ Anode/Cathode $100 \%$ \\ Atmospheric \\ Anode/cathode-0.175/0.417 Nl $\mathrm{min}^{-1}$
}

Start-up AST

1) Potential hold at $0.1 \mathrm{~V}$ for $2.5 \mathrm{~min}$

$\downarrow$ Slow ramp at $0.1 \mathrm{~V} \mathrm{~s}^{-1}$ rate

2) Potential hold at $1 \mathrm{~V}$ for $4 \mathrm{~min}$

$\downarrow$ Fast ramp at $1.5 \mathrm{~V} \mathrm{~s}^{-1}$ rate

3) Peak at $1.5 \mathrm{~V}$

$\downarrow$ Fast ramp at $1.5 \mathrm{~V} \mathrm{~s}^{-1}$ rate

4) Potential hold at $1 \mathrm{~V}$ for $2 \mathrm{~min}$

$\mathrm{H}_{2} / \mathrm{N}_{2}-0.06 / 0.06 \mathrm{Nl} \mathrm{\operatorname {min } ^ { - 1 }}$ the reinforcement, however some large precipitates are also located at $\mathrm{CCL} /$ membrane interface (Figs. 11A-11C). For the MEA aged under SU-AST in zero-gradient cell, the precipitate band is located near the CCL/membrane interface with some large Pt precipitates appearing to precipitate in the CCL, probably inside the ionomer (Fig. 11E). The Pt precipitated in the membrane (near the reinforcement) when the anode is fed with $\mathrm{H}_{2}$ and the cathode with air (real start-up), while the $\mathrm{Pt}$ band is shifted in the cathode/membrane interface or in the CCL (inside the ionomer) in the case of $\mathrm{H}_{2} / \mathrm{N}_{2}$ operations when high hydrogen concentration is reached also at the cathode side. Elongated precipitates were found in the case of startup AST: the formation of such a large precipitate could be characteristic of the fast voltage sweep and wide potential window adopted.

Regarding the $\mathrm{Pt}$ ions, precipitation at the membrane anode/ interface (reported in SI-3), observed for cathode inlet/middle samples and SU-AST,but not for cathode outlet sample, could be related to the large amount of Pt ions that diffuses/migrates through the membrane (not precipitating over the reinforcement). They were smaller respect to larger precipitate at cathodic side and could indicate that some ions cross the membrane without being reduced by hydrogen crossover.

Despite the differences observed in the Pt band formation in air and inert atmosphere, that could enhance the degradation over a larger 
(A)

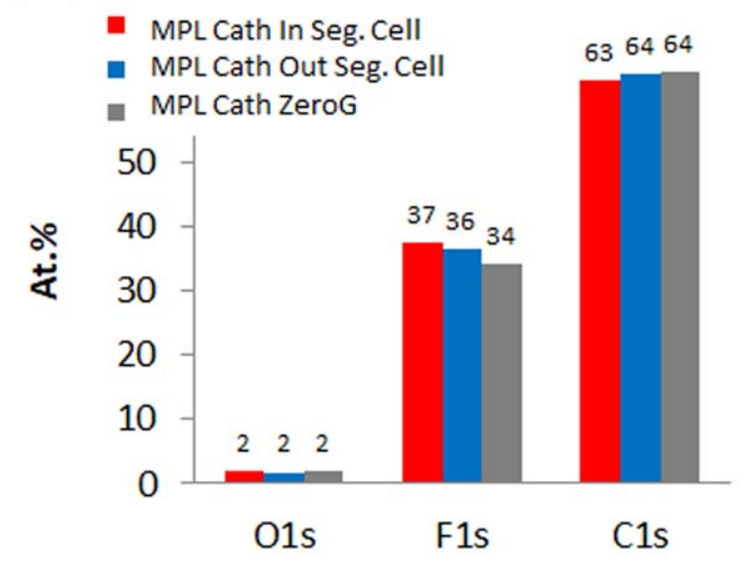

\section{(C)}

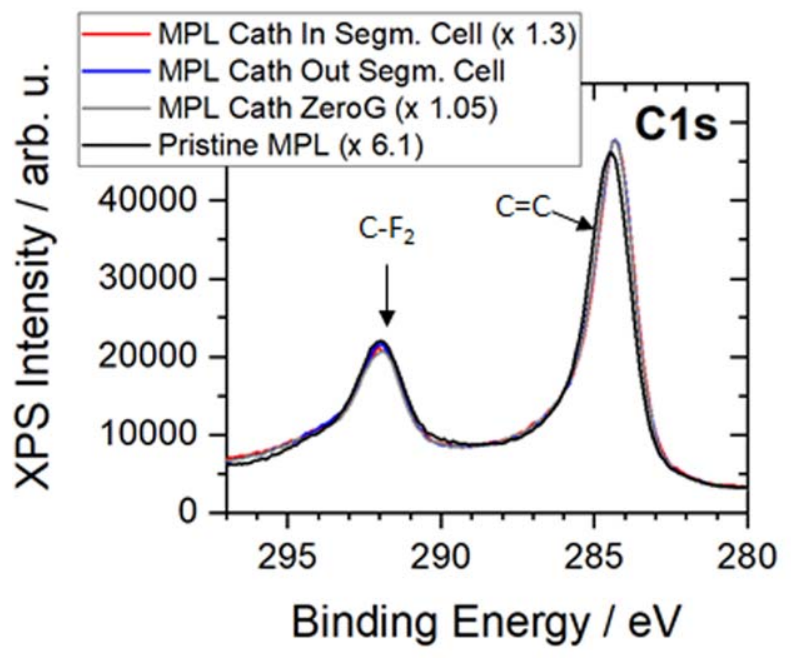

(B)

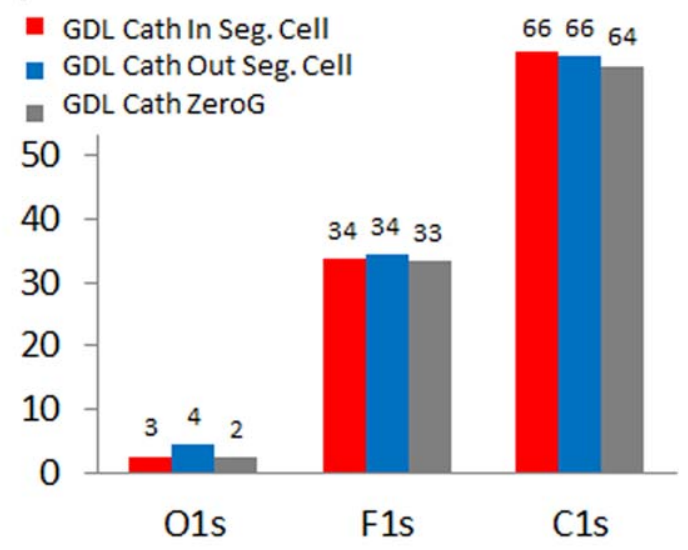

(D)

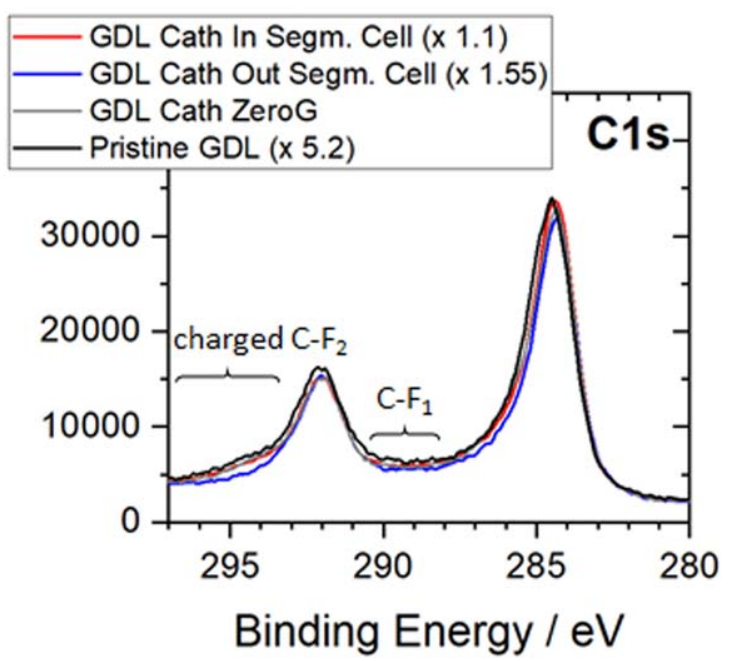

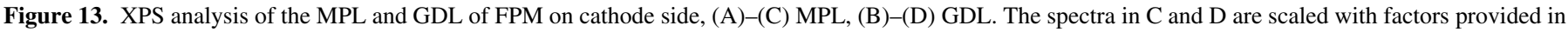
brackets in the legend to allow better comparing of the shapes of the signals.

number of start-up cycles, the mechanism of platinum dissolution and diffusion/precipitation within the polymer electrolyte is the dominant physical process underlying performance loss observed in start-up operations.

From TEM images the Pt particle size distribution were calculated, and results are reported in Fig. 12.

The average particle values are quite similar for all the samples and around $3 \mathrm{~nm}$ with a standard deviation close to $2 \mathrm{~nm}$. Looking at the aged samples, the protocols showing the main similarities are collected at the cathode inlet of the segmented-cell and during the start-up AST. They show the same mean particle diameter (i.e. $3.4 \mathrm{~nm}$ ) and a similar particle distribution which is slightly wider than in SEG 2/3 and SEG 4. Larger particles (out of $20 \mathrm{~nm}$ abscissa scale in the histogram) were detected, in contrast with the other samples. As reported in literature ${ }^{64,65}$ due to voltage cycling, the particle size tends to increase for the Ostwald-ripening mechanism. Probably due to the small number of cycles and the different mechanism of dissolution involved at high potential the effect on particles size distribution is minor. In conclusion, the presence of large Pt agglomerate and the pronounced ECSA loss are good indicator that the catalyst material is severely stressed under wide voltage cycling.

To evaluate the coupling of CCL degradation with possible aging of the cathode side GDL/MPL related to high cathode potential occurring during start-up operation, the GDL backing and MPL samples were analyzed by means of XPS. In Figs. 13A and 13B XPS elemental analysis of aged MPL and GDL samples are reported, respectively. Apparently, the elemental concentrations of $\mathrm{C}, \mathrm{F}$ and $\mathrm{O}$ do not differ significantly in the three samples (Cath ZeroG: sample from the zero-gradient cell test, Cath In Seg. Cell: sample from SEG 1 of the m-SFC; and Cath Out Seg. Cell: sample from SEG 4 of the $\mathrm{m}$-SFC). To obtain more detailed insight on possible GDL and MPL aging, the $\mathrm{C} 1 \mathrm{~s}$ detailed spectra are provided in Figs. 13C and 13D showing two prominent peaks due to $\mathrm{C}-\mathrm{F}_{2}$ stemming from the binder and $\mathrm{C}-\mathrm{C}$ stemming from the carbon fibers. ${ }^{66}$ Obviously, the three samples of the MPL exhibit almost identical shape (Fig. 13C) lacking any indication for material aging. In Fig. 13D the spectral regions are labelled where signals from degraded GDLs are expected ${ }^{66}$ (charged $\mathrm{C}-\mathrm{F}_{2}$ and $\mathrm{C}-\mathrm{F}_{1}$ ). In this context, the defluorination of the binder resulting in an additional $\mathrm{C}-\mathrm{F}_{1}$ peak around $288 \mathrm{eV}$ is not observed. However, C1s spectra from SEG1 of the m-SFC and the zero-gradient cell exhibit a shoulder at $>292 \mathrm{eV}$ which is typically attributed to electrically charged binder (due to X-ray impact), likely caused by a kind of detachment between the binder and the conducting carbon fibers. It needs to be mentioned that the shoulder is very tiny compared to similar peaks of severely aged GDL. ${ }^{67}$ So, coupling effect of degradation between CCL and GDL is minor. 


\section{Conclusions}

A detailed investigation of start-up operation protocols, in singlecell hardware with capability to monitor local effects was conducted to evaluate the replicability of real-world operation by proper AST.

As a basis for the evaluation of the AST protocols representativeness, two operating profile that mimic start-up/shut-down operation were analyzed without/with the adoption of strategies to mitigate the degradation, consisting in suppressing shut-down and having a low temperature air start.

It has been demonstrated that the reference protocol (DoE AST for the catalyst support degradation) allows to reproduce the SU/SD operations without mitigation strategies (i.e. $\mathrm{T}=80^{\circ} \mathrm{C}$ and low flow rate) in a consistent manner. Having regard to the specific protocol adopted, it was observed that ten cycles of the catalyst support AST accurately reproduced the performance loss caused by one cycle of SU/SD. Moreover, the AST accelerates the ageing by a 6 factor. Despite the good predictability, a heterogeneous degradation along the flow field was observed, due to local potential asymmetry between the SU/SD operations, i.e. SU potential $=1.4 \mathrm{~V}$ vs RHE, SD potential $=1.3 \mathrm{~V}$ vs RHE, and the consequent variation of the potentials as a result of concomitant degradation.

To perform durability testing under "real world conditions," or mitigated SU/SD, appropriate mitigation strategies were introduced, which have been adapted for single-cell test based on statistical analysis of data from test vehicles. Generally, they were effective to mitigate the CCL degradation in contrast to the unmitigated protocol. However, after 200 cycles a strong heterogeneous degradation was observed at cathode inlet/anode outlet region. While the shut-down operation is effectively mitigated, the restart causes a local voltage cycling till $1.5 \mathrm{~V}$ at cathode inlet region.

The catalyst support AST at $30{ }^{\circ} \mathrm{C}$, was ineffective to reproduce this mechanism so, to overcome this limitation a new start-up AST protocol was developed in order to mimic the local potential profile of mitigated start-up. The new start-up protocol can be used to effectively predict the performance losses with a degradation rate equal to one. The introduction of a voltage profile from $0.1 \mathrm{~V}$ vs RHE to $1.5 \mathrm{vs}$ RHE boosts the formation/reduction of Pt-oxides resulting in an accelerated $\mathrm{Pt}$ dissolution/migration/agglomeration, while the low temperature mitigates the carbon oxidation reaction. Electrochemical and ex situ analysis confirmed that the observed degradation is mainly attributable to a $\mathrm{Pt}$ dissolution mechanism but with not negligible differences in the Pt band formation under air atmosphere, that could enhance the degradation at higher number of start-up cycle.

\section{Acknowledgments}

This project has received funding from the Fuel Cells and Hydrogen 2 Joint Undertaking under grant agreement No. 779565 (ID-Fast). This Joint Undertaking receives support from the European Union's Horizon 2020 research and innovation program.

\section{ORCID}

Andrea Bisello (iD https://orcid.org/0000-0002-1313-3078

Elena Colombo (iD https://orcid.org/0000-0002-2288-8704 Andrea Baricci (iD https://orcid.org/0000-0003-2331-7222 Claudio Rabissi (iD https://orcid.org/0000-0002-2734-8432 Pawel Gazdzicki (D) https://orcid.org/0000-0002-5728-7861 Andrea Casalegno (iD https://orcid.org/0000-0002-3396-4979

\section{References}

1. B. Heid, M. Linder, A. Orthofer, and M. Wilthaner, "Hydrogen: the next wave for electric vehicles?" McKinsey Center for Future Mobility (2017), https://www. mckinsey.com/industries/automotive-and-assembly/our-insights/hydrogen-thenext-wave-for-electric-vehicles.

2. Editorial, "A future for hydrogen in European transportation." Nature Catalysis, $\mathbf{3}$, 91 (2020).

3. D. A. Cullen, K. C. Neyerlin, R. K. Ahluwalia, R. Mukundan, K. L. More, R. L. Borup, A. Z. Weber, D. J. Myers, and A. Kusoglu, "New roads and challenges for fuel cells in heavy-duty transportation." Nature energy, 6, 1 (2021).
4. F. B. Nygaard, S. Veltzé, S. Rosini, F. Micoud, J. Hunger, and T. Jungman, $F C H-$ JU framework, Stack-Test Project, Test Module D-03: Start/Stop Durability, (2015), retrieved from http://stacktest.zsw-bw.de/media-centre/test-modules.html.

5. T. Zhang, P. Wang, H. Chen, and P. Pei, Appl. Energy, 223, 249 (2018).

6. C. A. Reiser, L. Bregoli, T. W. Patterson, J. S. Yi, J. D. Yang, M. L. Perry, and T. D. Jarvi, Electrochem. Solid-State Lett., 8, A273 (2005).

7. A. Lamibrac, G. Maranzana, J. Dillet, O. Lottin, S. Didierjean, J. Durst, L. Dubau, F. Maillard, and M. Chatenet, Energy Procedia, 29, 318 (2012).

8. T. Gaumont, G. Maranzana, O. Lottin, J. Dillet, S. Didierjean, J. Pauchet, and L. Guétaz, Int. J. Hydrogen Energy, 42, 1800 (2017).

9. N. Macauley, D. D. Papadias, J. Fairweather, D. Spernjak, D. Langlois, R. Ahluwalia, K. L. More, R. Mukundan, and R. L. Borup, J. Electrochem. Soc. 165, F3148 (2018).

10. Q. Shen, M. Hou, D. Liang, Z. Zhou, X. Li, Z. Shao, and B. Yi, J. Power Sources, 189, 1114 (2009)

11. J. Dillet, D. Spernjak, A. Lamibrac, G. Maranzana, R. Mukundan, J. Fairweather, S. Didierjean, R. L. Borup, and O. Lottin, J. Power Sources, 250, 68 (2014).

12. J. Durst, A. Lamibrac, F. Charlot, J. Dillet, L. F. Castanheira, G. Maranzana, L. Dubau, F. Maillard, M. Chatenet, and O. Lottin, Appl. Catal. B Environ., 138-139, 416 (2013).

13. T. Mittermeier, A. Weiß, F. Hasché, G. Hübner, and H. A. Gasteiger J. Electrochem. Soc., 164, F127 (2017).

14. T. Mittermeier, A. Weiß, F. Hasché, and H. A. Gasteiger, J. Electrochem. Soc., 165 F1349 (2018)

15. Y. Yu, H. Li, H. Wang, X.-Z. Yuan, G. Wang, and M. Pan, J. Power Sources, 205 10 (2012).

16. C. A. Reiser, "Homogenous gas in shut down fuel cells." World Intellectual Property Organization International Bureau, Patent WO2010056224 (2010), https://patentscope.wipo.int/search/en/detail.jsf?docId=WO2010056224.

17. T. Skiba, D. D. Jayne, P. A. Grubb, R. Grover, T. M. Remmers, and W. E. Sedlacek, "Fuel Cell Voltage Control." United States Patent, US 7,041,405 B2 (2006).

18. A. Oyarce, E. Zakrisson, M. Ivity, C. Lagergren, A. B. Ofstad, A. Bodén, and G. Lindbergh, J. Power Sources, 254, 232 (2014)

19. Y. Y. Jo, E. Cho, J. H. Kim, T.-H. Lim, I.-H. Oh, S.-K. Kim, H.-J. Kim, and J. H. Jang, J. Power Sources, 196, 9906 (2011).

20. X. Z. Yuan, H. Li, S. Zhang, J. Martin, and H. Wang, J. Power Sources, 196, 9107 (2011).

21. I. Bloom et al., J. Power Sources, 243, 451 (2013).

22. T. Bednarek and G. Tsotridis, Data Br., 31, 105945 (2020).

23. T. Bednarek and G. Tsotridis, J. Power Sources, 473, 228319 (2020).

24. C. Rabissi, M. Zago, P. Gazdzicki, L. Guétaz, S. Escribano, L. Grahl-Madsen, and A. Casalegno, J. Power Sources, 404, 135 (2018)

25. C. Rabissi, P. Gazdzicki, L. Guétaz, S. Escribano, L. Grahl-Madsen, A. Baricci, and A. Casalegno, J. Power Sources, 397, 361 (2018).

26. P. Piela, T. E. Springer, J. Davey, and P. Zelenay, J. Phys. Chem. C, 111, 6512 (2007).

27. E. Brightman and G. Hinds, J. Power Sources, 267, 160 (2014).

28. C. Rabissi, E. Brightman, G. Hinds, and A. Casalegno, Int. J. Hydrogen Energy, 43, 9797 (2018).

29. M. M. Mench and C. Y. Wang, J. Electrochem. Soc., 150, A79 (2003)

30. M. Noponen, T. Mennola, M. Mikkola, T. Hottinen, and P. Lund, J. Power Sources, 106, 304 (2002).

31. C. Wieser, A. Helmbold, and E. Gülzow, J. Appl. Electrochem., 30, 803 (2000)

32. A. B. Geiger, R. Eckl, A. Wokaun, and G. G. Scherer, J. Electrochem. Soc., 151 A394 (2004)

33. J. J. Gagliardo, J. P. Owejan, T. A. Trabold, and T. W. Tighe, "Nucl. Instruments Methods Phys. Res. Sect. A Accel. Spectrometers.” Detect. Assoc. Equip., 605, 115 (2009).

34. S. J. C. Cleghorn, C. R. Derouin, M. S. Wilson, and S. Gottesfeld, J. Appl. Electrochem., 28, 663 (1998).

35. G. Tsotridis, A. Pilenga, G. De Marco, and T. Malkow, EU Harmonised Test Protocols for PEMFC MEA testing in single cell configuration for automotive applications (2015), EUR - Scientific and Technical Research Reports.

36. S. K. Roy and M. E. Orazem, J. Electrochem. Soc., 154, B883 (2007).

37. H. A. Gasteiger, S. S. Kocha, B. Sompalli, and F. T. Wagner, Appl. Catal. B Environ., 56, 9 (2005).

38. US DOE, Fuel Cells 2016 Multi-Year Research, Development, and Demonstration Plan (2016), retrieved from https://energy.gov/sites/prod/files/2016/10/f33/fcto_ myrdd_fuel_cells.pdf.

39. K. C. Neyerlin, W. Gu, J. Jorne, and H. A. Gasteiger, J. Electrochem. Soc., 153 A1955 (2006).

40. G. S. Harzer, J. N. Schwämmlein, A. M. Damjanović, S. Ghosh, and H. A. Gasteiger, J. Electrochem. Soc., 165, F3118 (2018).

41. D. R. Baker, D. A. Caulk, K. C. Neyerlin, and M. W. Murphy, J. Electrochem. Soc., 156, B991 (2009).

42. D. R. Baker, C. Wieser, K. C. Neyerlin, and M. W. Murphy, ECS Trans., 3, 989 (2006).

43. T. A. Greszler, D. Caulk, and P. Sinha, J. Electrochem. Soc., 159, F831 (2012).

44. S. B. Rice et al., Metrologia, 50, 663 (2013).

45. E. Colombo, A. Bisello, A. Baricci, and A. Casalegno, Journal of The Electrochemical Society, 1, 1 (2021).

46. A. Lamibrac, G. Maranzana, O. Lottin, J. Dillet, J. Mainka, S. Didierjean, A. Thomas, and C. Moyne, J. Power Sources, 196, 9451 (2011)

47. S. A. Vilekar and R. Datta, J. Power Sources, 195, 2241 (2010) 
48. L. Cheng et al., Adv. Energy Mater., 10, 2000623 (2020).

49. P. T. Yu, W. Gu, R. Makharia, F. T. Wagner, and H. A. Gasteiger, ECS Trans., 3, 797 (2006).

50. T. Mittermeier, A. Weiß, F. Hasché, G. Hübner, and H. A. Gasteiger, J. Electrochem. Soc., 164, F127 (2017).

51. G. Maranzana, A. Lamibrac, J. Dillet, S. Abbou, S. Didierjean, and O. Lottin, J. Electrochem. Soc., 162, F694 (2015).

52. T. E. Springer, T. A. Zawodzinski, M. S. Wilson, and S. Gottesfeld, J. Electrochem. Soc., 143, 587 (1996).

53. J. N. Schwämmlein, P. J. Rheinländer, Y. Chen, K. T. Freyer, and H. A. Gasteiger, J. Electrochem. Soc., 165, F1312 (2018).

54. J. X. Wang, J. Zhang, and R. R. Adzic, J. Phys. Chem. A, 111, 49 (2007)

55. B. D. Gould, K. S. Lyons, and O. A. Baturina, United States Patent US20110008686A1, Performance recovery of a fuel cell (2011), https://patents. google.com/patent/US20110008686A1.

56. V. A. Sethuraman and J. W. Weidner, Electrochim. Acta, 55, 5683 (2010)

57. X. Zhang, L. Guo, and H. Liu, J. Power Sources, 296, 327 (2015).
58. T. A. Greszler, D. Caulk, and P. Sinha, J. Electrochem. Soc., 159, F831 (2012).

59. A. Kneer, J. Jankovic, D. Susac, A. Putz, N. Wagner, M. Sabharwal, and M. Secanell, J. Electrochem. Soc., 165, F3241 (2018).

60. D. J. Myers, X. Wang, M. C. Smith, and K. L. More, J. Electrochem. Soc., 165 F3178 (2018)

61. A. Z. Weber and A. Kusoglu, J. Mater. Chem. A, 2, 17207 (2014).

62. H. Yu, A. Baricci, A. Bisello, A. Casalegno, L. Guetaz, L. Bonville, and R. Maric, Electrochim. Acta, 247, 1155 (2017).

63. H. Yu, A. Baricci, A. Casalegno, L. Guetaz, L. Bonville, and R. Maric Electrochim. Acta, 247, 1169 (2017).

64. R. Borup et al., Chem. Rev., 107, 3904 (2007).

65. R. L. Borup, J. R. Davey, F. H. Garzon, D. L. Wood, and M. A. Inbody, J. Power Sources, 163, 76 (2006).

66. D. G. Sanchez, T. Ruiu, I. Biswas, M. Schulze, S. Helmly, and K. A. Friedrich, J. Power Sources, 352, 42 (2017).

67. D. G. Sanchez, T. Ruiu, I. Biswas, K. A. Friedrich, J. Sanchez-Monreal, and M. Vera, ECS Trans., 64, 603 (2014). 